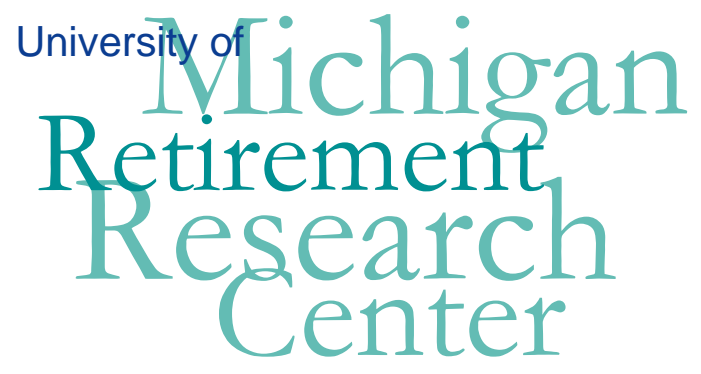

Working Paper

WP 2006-135

How Did the Elimination of the Earnings
Test Above the Normal Retirement Age
Affect Retirement Expectations?
Pierre-Carl Michaud and Arthur van Soest

\begin{tabular}{|l|l|l|l|l}
\hline $\mathrm{M}$ & $\mathrm{R}$ & Project \#: UM06-13 \\
\hline
\end{tabular} 


\title{
"How Did the Elimination of the Earnings Test Above the Normal Retirement Age Affect Retirement Expectations?”
}

\author{
Pierre-Carl Michaud \\ RAND \\ Arthur van Soest \\ RAND \& Tilburg University
}

October 2006

\author{
Michigan Retirement Research Center \\ University of Michigan \\ P.O. Box 1248 \\ Ann Arbor, MI 48104 \\ http://www.mrrc.isr.umich.edu/
}

(734) 615-0422

\section{Acknowledgements}

This work was supported by a grant from the Social Security Administration through the Michigan Retirement Research Center (Grant \# 10-P-98358-5). The findings and conclusions expressed are solely those of the author and do not represent the views of the Social Security Administration, any agency of the Federal government, or the Michigan Retirement Research Center.

Regents of the University of Michigan

David A. Brandon, Ann Arbor; Laurence B. Deitch, Bingham Farms; Olivia P. Maynard, Goodrich; Rebecca McGowan, Ann Arbor; Andrea Fischer Newman, Ann Arbor; Andrew C. Richner, Grosse Pointe Park; S. Martin Taylor, Gross Pointe Farms; Katherine E. White, Ann Arbor; Mary Sue Coleman, ex officio 


\title{
How Did the Elimination of the Earnings Test Above the Normal Retirement Age Affect Retirement Expectations?
}

\author{
Pierre-Carl Michaud and Arthur van Soest
}

\begin{abstract}
Using panel data models and the seven available waves of the Health and Retirement Study, we look at the effect of the 2000 repeal of the earnings test above the normal retirement age on retirement expectations of workers aged 51 to 61 - their probabilities to work past age 62 and 65 as well as the age at which they expect to start claiming old age social security benefits.. We use administrative records linked to the HRS to create variables that accurately reflect the change in financial incentives. For men, we find results in line with theoretical predictions on the probability to work after age 65. For example, men whose marginal wage rate increased when the earnings test was repealed, showed the largest increase in the probability to work full-time past normal retirement age. For women, we do not find significant results, possibly due to omitting spouse benefits and their interaction with the earnings test. We also do not find significant evidence of effects of the repeal of the earnings test on the probability to work past age 62 or the expected claiming age. On the other hand, for those reaching the normal retirement age, deviations between the age at which Social Security benefits are actually claimed and the previously reported expected age are more negative in 2000 than in 1998, suggesting that the repeal has increased claiming immediately after reaching normal retirement age. Since our calculations show that the tax introduced by the earnings test was small when accounting for actuarial benefit adjustments and differential mortality, our results suggest that although workers form expectations in a way consistent with forward-looking behavior, they misperceive the complicated rules of the earnings test.
\end{abstract}

\section{Authors' Acknowledgements}

This research was funded by SSA through MRRC. The authors thank participants of the MRRC workshop in April 2006 for useful comments. 


\section{Introduction}

While several papers study the effect of the social security earnings test on actual retirement (e.g., Leonesio, 1990; Haider and Loughran, 2005), little is known about how workers in their late fifties or early sixties who are not yet affected by the earnings test adjust their retirement plans and expectations in response to such an earnings test taxing away earnings later in life. The Senior Citizens' Freedom to Work Act of 2000 provides an excellent example of a natural experiment that can be used to look at this issue, involving a change in the effective tax structure across age groups. We analyze the effect of the repeal of the earnings test above the normal retirement age (NRA) in 2000 on expectations about employment and social security claiming after NRA of those who were younger than NRA at the time of the repeal.

Recent studies looking at the earnings test find large responses to the earnings test in terms of labor supply, earnings, claiming of benefits as well "bunching" of workers" earnings at the minimum exempt amount (Friedberg, 2000; Tran, 2004; Haider and Loughran, 2005). This is despite the fact that benefits lost due to the earnings test are reimbursed at a later age trough an actuarial adjustment. This actuarial adjustment is generally believed to be actuarially fair for recent cohorts. One interpretation of this finding is that workers are simply myopic instead of forward looking. A necessary condition for workers to be forward-looking is that the expectations of their future behavior respond to changes in the incentive structure over the life-cycle. If forward looking workers in their late fifties and early sixties are aware of the repeal of the earnings test, they may adjust the expectations about their future labor market behavior. They may also change their current behavior and for example substitute labor supply intertemporally so as to maximize lifetime utility. In the end, the desirability of the earnings test depends on its disincentive effects on lifetime labor supply and wealth. ${ }^{3}$ Hence, looking at changes in expectations following the repeal contributes to understanding better the life-cycle responses to the rules of a program like the Old Age Social Insurance benefits but also to understanding how workers' plans for retirement are affected by the tax structure.

\footnotetext{
${ }^{3}$ Other considerations on the desirability of the earnings test include whether its elimination would induce workers to retire "too early", not taking into account the lower benefits level (Gruber and Orszag, 2003). This could have damaging implications for poverty in old age. Gustman and Steinmeier (2004) point to the fact that the elimination of the earnings test could affect the short-term viability of the Social Security Trust Fund.
} 
This paper first documents the size of the taxes induced by the earnings test in the population covered by the Health and Retirement Study, using administrative earnings records from the Social Security Administration. These calculations take account of the actuarial adjustment and allow for differential mortality profiles using survival probabilities accounting for the heterogeneity in subjective mortality beliefs elicited in the HRS. Second, we look at the effect of the repeal of the earnings test on expectations of workers not yet directly affected by the test in 2000 . We consider expectations to work full-time past ages 62 and 65 as well as the age at which workers expect to start collecting Social Security benefits. We also look at the extent to which workers later deviate from these expectations because of the repeal of the earnings test. The identification strategy makes use of the pre-repeal tax rates calculated in the first step.

The rest of the paper is structured as follows. In Section 2, we first discuss the nature of the earnings test and sketch a stylized life-cycle framework of individual behavior that helps to understand how people can react to eliminating the earnings test in a static and in a life-cycle setting. Then we discuss the expectations variables we want to analyze and present some descriptive statistics for the time periods before and after the policy change, illustrating the fact that there have been substantial changes in retirement expectations (section 3). Section 4 discusses the construction of the financial incentive variables from administrative SSA records linked to HRS, which we use to answer the question whether the earnings test is a still a tax when the actuarial adjustment is taken into account. In section 5, we present the estimates of some empirical models for panel data, based on a difference in differences approach and random effects panel data models. That approach rests on the tax rates constructed in Section 4. Section 6 looks at the effect of elimination of the earnings test on actual behavior, particularly the actual age at which people start claiming Social Security benefits. Section 7 concludes.

\section{The Earnings Test and Its Potential Effects on Labor Supply}

Details on the rules of Old Age Social Insurance (OASI) benefits since its inception in 1951, including the working of earnings tests for several age groups, are presented in Benitez-Silva and Heiland (2005). Here we focus on the features that are relevant for our study on the effect of eliminating the earnings test for the age group 6570 in 2000. These are presented in Table 1. 
To be more precise, the earnings test was abolished for people above the normal retirement age (NRA), ${ }^{4}$ which was 65 years in 2000, but has been gradually increased since 2003. It was 65 years and 4 months for individuals turning 65 in 2004 and will be 65 years and 10 months for those reaching age 65 in 2007. An earnings test still applies for OASI benefits received before NRA. As shown in Table 1, if someone claims OASI benefits before reaching NRA, the OASI benefit is reduced by one US dollar of every two dollars earned above an exempt amount. This exempt amount grew from $\$ 7,440$ per year in 1992 (the year of the first wave of HRS) up to \$11,640 in 2004 in nominal terms.

A similar test applied until April 7 of the year 2000 to earnings for those who claimed benefits and had positive earnings after their NRA. ${ }^{5}$ The OASI benefit was reduced by one dollar for every three dollars earned in excess of the exempt amount, which was $\$ 14,500$ in $1998 .^{6}$ Thus from a static, one period point of view, the earnings test is similar to a means tested benefit. In a multi-period setting however, it should be kept in mind that someone gets compensated for not receiving OASI benefits in a given year by receiving more in the future. This is illustrated in the final two rows of the table. If individuals ${ }^{7}$ postpone claiming for another year and have not yet reached the NRA, they get 6.8 percent (ARF, the actuarial reduction factor) higher benefits every year in the future than they would get were they to retire and start claiming immediately. On average this appears to be an actuarially fair growth rate of future old age benefits. A different rate applies after the NRA. Postponing claiming for another year after NRA used to pay somewhat less, as is illustrated in the last line of the table (DRC: delayed retirement credit). The compensation for postponing claiming in the years after NRA was $7.0 \%$ in 2004 and will eventually reach $8 \%$ for future cohorts reaching NRA. The delayed

\footnotetext{
${ }_{5}^{4}$ Social Security refers to the Normal Retirement Age as the Full Retirement Age (FRA).

${ }^{5}$ On April $7^{\text {th }} 2000$, President Clinton signed the "Senior Citizen Freedom to Work Act". Congress approved a preliminary version proposed on March $1^{\text {st }}$ and the Senate approved the amended version on March $22^{\text {nd }}$. The desirability of the reform had already been emphasized in his 1999 State of the Union Address: "we should eliminate the limits on what seniors on Social Security can earn.". The vote was unanimous in the Senate in favor of the repeal. On March $23^{\text {rd }}$, the passing of the measure in the Senate surfaced in popular media (New York Times, March $23^{\text {rd }} 2000$ ). There was some discussion in the regular press about the upcoming reform. On February $20^{\text {th }}$, the New York Times reports that the president already signaled his attention to sign the bill if passed which shows that there was little uncertainty about the possibility that the law would be in effect before the end of the year. The repeal was in effect for earnings after December $31^{\text {st }} 1999$.

${ }^{6}$ In the year a worker reaches the normal retirement age, there is a special exemption for earnings in that calendar year. This exemption was $\$ 17,000$ in 2000 . See $\$ 1803.2$ of the Social Security Handbook.

${ }^{7}$ For couples, the situation is often more complicated, due to spouse benefits. For those collecting spouse benefits, the earnings test is applied on their spouse's earnings. We ignore this issue in the current paper.
} 
retirement credit is roughly fair for younger cohorts, while it was actuarially less than fair for older cohorts. For those born prior to 1926 , DRC was $3.5 \%$.

For earnings lost before NRA, the actuarial adjustment starts at NRA. Each full monthly check lost gives rise to a one month actuarial adjustment. Hence someone who claims at age 62 and loses all his checks in that year because of high earnings will receive the same check as someone who claimed at age 63 from the point where they reach NRA onwards. Before NRA however, the one who claimed early (and lost his first year benefit), will get checks from age 63 to the NRA that do not include the actuarial adjustment.

\section{A Two-Period Model}

Prior to 2000, the actuarial adjustment operated in the same way after the NRA as before the NRA. The only difference was that the actuarial adjustment (delayed retirement credit), was applied the following year rather than being restricted to after a later age. In a static one period model of labor supply, this compensation is ignored. In a dynamic framework, optimizing individuals will take this increase in future benefits into account when making their labor supply decisions, under the condition that they are aware of it. Whether the latter is indeed the case is not so clear, see, e.g., Friedberg (2000) who argues that their labor supply behavior reveals that they are not. Gruber and Orszag (2003) show that in one of the leading tax guides, no mention of the actuarial adjustment is made. To understand the labor supply effects of the earnings test in a dynamic framework, we construct a simple two-period model along the lines of Disney and Smith (2001). Spouses and spouse benefits are ignored. For convenience, we present the model for a single male.

For simplicity, assume individuals make decisions over two periods. In period 1, the individual can decide to claim OASI benefits or not, and can also choose hours of work $h$. In period 2, the individual claims in any case (whether he was claiming in period 1 or not), and does not work. The hourly wage rate in the first period is denoted by $w$. If he was claiming already in period 1, the individual gets pension $P_{1}$ in period 2. Define $P_{2}=P_{1}+\delta P_{0}$ to be the benefit if the individual delays claiming to period 2 . The actuarial adjustment factor is $\delta \geq 0$. Individuals discount period 2 income at a rate $\theta \geq 0$ (which includes mortality risk). Hence, the adjustment is perceived as unfavorable if $\delta<1 / \theta$, in 
which case the individual prefers income $P_{0}$ in the first period to $\delta P_{0}$ in the second period. The case where an individual is myopic is represented by $\theta=0$. In this case, the individual does not consider future consequences of current decisions.

If the individual does not claim in the first period, the total discounted value of income is

$$
Y=w h+\theta P_{2}
$$

If the individual decides to claim and work in the first period, income can be affected by the earnings test. The earnings test rule is defined by two parameters: the maximum earnings allowed without being taxed $E$ (the exempt amount) and the rate at which benefits are taxed away by the earnings test for each dollar above $E$, the "tax rate" $\tau$.

Three situations can occur depending on how many hours the individual decides to work.

If $h<E / w$, the earnings test does not reduce benefits, and the present value of total income is

$$
Y=w h+P_{0}+\theta P_{1}
$$

If hours are above the threshold (or, in other words, earnings are above $E$ ), benefits are reduced. The reduction is $e=\tau(w h-E)$ up to complete exhaustion of the benefit $P_{0}$. Exhaustion will occur when the individual works $h_{\max }$ hours, defined as

$$
\begin{aligned}
& P_{0}=\tau\left(w h_{\text {max }}-E\right) \\
& h_{\text {max }}=\left(P_{0} / \tau+E\right) / w
\end{aligned} .
$$

If the benefit is completely lost, the individual gets $P_{2}=P_{1}+\delta P_{0}$ in the second period, the same as if he would not have claimed. Define $\pi=e / P_{0}$, the fraction of the benefit lost in period 1 . Hence, if benefits are not completely taxed away, the partial adjustment yields a benefit in the second period of $P_{1}+\pi \delta P_{0}$. SSA calculates the partial adjustments based on the number of months no check was collected. On the segment $h \geq E / w$ and $h<h_{\max }$, the present value of total income over the two periods is thus given by

$$
Y=w h+\left(P_{1}-\tau(w h-E)\right)+\theta\left(P_{1}+\pi \delta P_{0}\right)
$$


Finally, an individual who works more than $h_{\max }$ gets

$$
Y=w h+\theta P_{2}
$$

Note that (1) and (4) are equivalent in the case where desired hours are so high that it exhausts all benefits. This would not be true if there was no actuarial adjustment under the earnings test. In that case, we would essentially have $\pi=0$ instead of $\pi=e / P_{0}$. This will also be the relevant case for individuals who realize that they get a compensation for postponing claiming $(\delta>0)$ but do not realize that they are compensated in the same way if they have started to claim but their benefits are partially or completely taxed away by the earnings test; such individuals will base their decisions on the perception that $\pi$ equals zero.

For individuals who do not intend to work in period 1 or for those who want to work few hours such that their earnings are below the maximum allowed under the earnings test, it may still be profitable to delay claiming rather than to claim immediately. This is the case if the actuarial adjustment $\delta P_{1}$ is large enough to compensate for the lost benefits $P_{0}$. In this two period model, the condition for this is $\delta>1 / \theta$, i.e., the individual perceives the compensation for delayed claiming as more than fair.

To illustrate how expected income is affected by the earnings test, we consider the following example, corresponding to the situation of a worker at the normal retirement age having a $\$ 20$ wage rate per hour and a pension entitlement of $10,000 \$$ in the first and the second period (with the latter excluding the potential adjustment if less than the full benefit is claimed in period 1). We consider his decision just prior to the repeal of the earnings test at the normal retirement age. The tax rate is $33 \%$ and the exempt earnings maximum $E$ is $\$ 14,500$. The individual's subjective discount rate $\theta$ is assumed to be 0.97 and the actuarial adjustment $\delta$ is 0.75 which is perceived as unfair $(1 / 0.97=1.0302>0.75)$. We consider two situations when the individual is claiming in the first period. One is the actual situation where adjustment due to the earnings test is possible $(\pi>0)$ and the other one is the situation where the individual is unaware of the adjustment in case the earnings test applies $(\pi=0)$.

To summarize: 


$$
\begin{aligned}
& w=20, E=14,500, \delta=0.75 \\
& \tau=0.33, \theta=0.97, P_{1}=10,000
\end{aligned}
$$

Figure 1 presents this individual's "budget set", i.e., the present value of perceived total income as a function of hours of leisure (3000-hours of work) in period 1. If the individual does not claim in period 1 (dashed line), the budget set is linear (taxes are ignored in this stylized model). In the other two cases, the budget set is piecewise linear, with kinks at $h_{\min }=E / w=725$ hours of work (2275 hours of leisure) and $h_{\max }=h_{\min }+P_{0} /(\tau w)=2225$ (775 hours of leisure). The slopes of the flatter part in the middle, however, are quite different. If $\pi=0$, the slope is $(1-\tau) w=13.33$, since the individual perceives no compensation for the benefits that are taxed away. In this case, the individual may easily think that it is better not to claim. In the actual situation on the other hand, where $\pi=e / P_{0}$, the slope is much higher, because of the actuarial adjustment. To be precise, the slope in the flatter part is $13.33+\theta \delta \tau w=18.18$. The difference with the slope of 20 is due to the fact that the individual's subjective discount rate makes the actuarial adjustment unfair, so that the delayed receipt of benefits is still seen as a mild tax on earnings.

Abolishing the earnings test can have different effects on labor supply in the first time period, depending on where the individual would be on the budget curve in the presence of the earnings test and depending on whether or not he claims in the first period.

First consider someone who is claiming benefits in the presence of the earnings test, and works more than $h_{\max }$ hours (group A). Abolishing the earnings test will not change his marginal wage rate, but will have a negative income effect, since the benefit is completely taxed away under the earnings test. Hence, the repeal will reduce the work effort of this individual.

Next consider the group who claim benefits and work between $h_{\min }=E / \mathrm{w}$ and $h_{\max }$ in the presence of the earnings test (group B). This is the group which has some benefits taxed away by the earnings test. In this case, there is both a substitution and an income effect from abolishing the earnings test. With no earnings test, the worker gets more income which should reduce hours worked (an income effect). On the other hand, the increased marginal reward from an additional hour of work may also give him an 
incentive to increase labor supply (substitution effect). Hence the total effect is ambiguous.

Individuals just above or exactly at the kink $h_{\min }$ will want to work if the earnings test is eliminated, since for them, there is hardly any income effect. The income effect will be larger if the individual is closer to $h_{\max }$. We thus expect a positive effect on labor supply for those close to or at $h_{\min }$, and a smaller positive or possibly even negative effect for those close to $h_{\max }$. In our empirical work, we will exploit information from SSA earnings records to determine where individuals are before the earnings test is repealed and how close the respondents actually are to the two kinks.

For the group who claim benefits in period 1 and work less than $h_{\min }$ (group C), the earnings test is irrelevant - these people have, in the presence of the earnings test, so little earnings that the earnings test does not lead to reduced benefits. Their behavior will not change if the earnings test is abolished. ${ }^{8}$

Finally, consider the respondents who do not claim benefits as long as the earnings test applies. One reason for not claiming may be that actuarial adjustment is considered favorable, $\delta>1 / \theta$. In this case, abolishing the earnings test will not have any effect - this group (group D) will also not claim if the earnings test is eliminated.

A second group of non-claimants are those who perceive the actuarial adjustment as unfavorable $(\delta<1 / \theta)$ but misinterpret the rules of the earnings test and perceive $\pi=0$ (group E). Their perceived budget set in case of claiming will change if the earnings test is abolished, and this may induce them to start claiming. In figure 1, these are the people on the dashed line who work more than (approximately) 1200 hours - for them, as long as the earnings test applies, the present value of total income is perceived as higher if they do not claim. This changes if the earnings test is abolished. They will then claim and reduce their working hours due to a negative income effect. (There is no substitution effect since they come from the dashed line).

\footnotetext{
${ }^{8}$ In practice, measurement error or rigidities may imply that respondents are observed below the kink but actually are at the kink. In that case, abolishing the earnings test will have a positive effect on their labor supply (as in group B).
} 


\section{Data}

We use the Health and Retirement Study using all available cohorts in the waves 1992 - 2004. Table 2 presents the design of the complete HRS, illustrating when respondents were interviewed and how old they were at the time of the repeal. The original HRS cohort born 1931-1941 was first interviewed in 1992, the AHEAD cohort born before 1923 entered in 1993, the War Babies (born 1942-1947) and Child of Depression Age (CODA, born 1924-1930) entered in 1998, and the Early Boomers (EB, born 1948-1953) first participated in 2004, the last available wave. As Table 2 shows, the cohort directly affected by the repeal is the original HRS cohort, for whom the normal retirement age was 65 . When the earnings test was repealed in 2000, respondents of this cohort were between 59 and 69 years old. There is some heterogeneity in the delayed retirement credit available to workers who will be affected in the HRS cohort (from $5.12 \%$ to $6.70 \%$ in 2002 ).

Moreover, although their NRA is clearly after the year of the repeal, expectations of younger workers, particularly those in the War Babies cohort, can also be affected by the repeal. The delayed retirement they face, however, is more advantageous than the one their predecessors faced. Thus if they were aware of the DRC before the repeal and do not face liquidity constraints, the repeal is less likely to have had a large effect on them.

\subsection{Match with Social Security Earnings Records}

In order to obtain exact information on OASI entitlements and how these are affected by earnings and claiming decisions, we link respondent records with their earnings history records from Social Security. This has the advantage that we can accurately compute social security incentives faced by respondents. Without such records, it is difficult to capture life-time earnings (on which social security benefits are based) without imposing strong assumptions. Measurement error in earnings is an important problem when looking at the effects of the earnings test, as shown by Haider and Loughran (2005). We use administrative earnings records to compute benefit eligibility but also to compute the earnings profile for each respondent. We have access to records for the HRS, War Babies and CODA cohorts. The HRS asked respondents in 1992, 1998, and 2004 for permission to match their earnings records. We do not have access to the earnings records data for 2004 yet. Hence, we have no Social Security earnings data for the Early Boomers. 
There are two potential drawbacks of using earnings record matched with HRS respondents. First, Social Security earnings are top-coded at the maximum taxable earnings (presently about \$90,000). This applies to 6\% of respondents' 1991 (HRS) and 1999 (for WarBabies and CODA) earnings. If they are subject to the earnings test, most of these respondents would already lose their complete social security benefits when reaching the lower threshold of $\$ 90,000$. Hence, the classification of respondents in terms of the incentive they face due to the earnings test is hardly affected by that censoring.

Second, there are a fair number of respondents for whom a match to an SSA earnings record is not possible. In the HRS cohort, $75.1 \%$ of respondents have a successful match. For CODA and War Babies respondents, the match rates are much lower (50-60\%) than in the original HRS cohort. We will present some descriptive statistics for the two groups (those with and those without a match; see Table 4 below). It will turn out that in terms of observables the two samples do not differ much.

We use the Average National Wage Index constructed by the Social Security Administration to project earnings into the future. These earnings are needed to compute various measures of future retirement incentives. Over the period 1985-2003, the average growth rate was roughly $4 \%$. Over the same period, inflation (measured by the Consumer Price Index published by the Bureau of Labor Statistics) was on average 2.9\% per year, thus yielding an about 1\% real growth in earnings. Inevitably, constructing projected earnings profile introduces some "measurement" error. The maintained assumptions are that workers project to work the same hours as they currently work in the future, and that the growth rate of wages is the same across all groups of workers. Neither of these assumptions is likely to be completely correct. Still, we expect only a limited gain of replacing these projections by forecasts at an individual level. For example, a major impediment for forecasting individual earnings using the observed earnings profile in the cross-section or the panel is that they will suffer from strong selection due to retirement incentives.

\subsection{Sample Selection}

For our analysis, we select respondents aged 51 to 61 who report to be working for pay. We do this because the expectations questions we will examine are only asked to workers. This means we have an unbalanced sample where we follow respondents when age eligible and working. In 1992, the entire original HRS cohort is age eligible. In later 
waves, some HRS respondents have moved out of this age group. Some respondents aged 51-61 have already retired, but this number is low compared to after age 61 when workers become eligible for Social Security benefits on their own earnings record. The first major refreshment of the original HRS sample enters in 1998 with the introduction of the War Babies cohort, aged 51-56 in 1998. Finally, the Early Boomers refresh the sample in 2004. For most of the analysis, we will not use the Early Boomers because we do not have Social Security earnings records for them.

Table 3 gives the number of observations in each wave along with the number of observations for which we have Social Security Earnings Records (SS.Er). The sample generally gets smaller after 2000 until the Early Boomers cohort come in. The fraction of respondents with an SS.Er is large in early years and decreases because of lower match rates for War Babies in 1998. The low match rate in 2004 reflects the fact that we do not have any SS.Er for the Early Boomers.

\subsection{Descriptive Statistics}

Table 4 presents descriptive statistics of some background variables that we shall use in the analysis of expectations in the age 51-61 sample.

One aspect of workers' environment that may be important when analyzing the earnings test is the flexibility of their current job. If workers cannot change hours at their current employer, they need to change jobs to reduce hours (see, e.g., Hurd, 1996). This may be difficult, particularly for workers in their late 60 s because demand for workers of this age may be lower and search costs may be higher. Some information on job flexibility is available in the HRS as of 1996. We use two questions, for which the response rate is quite high (in the 90\%). The first refers to whether the respondent feels pressured by co-workers to retire before 65 . This is used to measure the general attitude of co-workers (and often employers) to older workers. The other question refers to whether the respondent thinks that a transition to a low demanding job is relatively easy at his current employer. This measures the flexibility to reduce work pressure, hours, or responsibilities at the current job. We code the answers as one (yes) if the respondent reports either "strongly agree" or "agree" and zero (no) otherwise. Over all waves, approximately one tenth of workers aged 51-61 think they are pressured to retire before 65 at their current employer. More than one quarter thinks that a transition to a low demanding job with the same employer is possible. 
Finally, we consider measures of current earnings, accumulated financial wealth (liquid = savings, stocks, bonds, CDs, IRAs) as well as real assets such as real estate and other assets, and whether the respondent has an occupational pension on his current job and, if so, of what type - defined benefit or defined contribution. The AIME is the average indexed monthly earnings, a measure of life-time earnings, computed using the SS.Er earnings records. It is the monthly equivalent of the average earnings over the 35 years of highest admissible Social Security earnings. It is the basis for the primary insurance amount (PIA) to which a worker is entitled as a benefit at the normal retirement age. The PIA is a piece-wise linear function of the AIME with two kink points and marginal tax rates of $0.9,0.4$ and 0.1 on the three segments. The median worker between age 51 and age 61 had an AIME of \$1578 in 1994, compared to \$2237 in 2002. These amounts are not adjusted for inflation (using the CPI \$1578 in 1994 dollars is \$1916 in 2002 dollars).

Differences in characteristics between the overall sample and the sample with matched SS.Er earnings records appear to be relatively small, except for 2004 where the entire Early Boomers cohort does not have a match. Apart from this difference, some under representation of blacks is found, as well some difference in total financial wealth.

We focus on three measures of expectations. The first one is the subjective probability to work full-time in any period past age 65 . This measure is relatively well documented, see, e.g., Hurd (1999) and Chan and Stevens (2004). The exact wording of the question is "Thinking about work generally and not just your present job, what do you think are the chances that you will be working full-time after you reach 65 ”. The answer is a number between 0 and 100 (in 1992 between 0 and 10 which is adjusted). We refer to this question as $\mathrm{P}(65)$. The question is only asked when the respondent provided a positive probability to another probability question that asks for the probability of working full-time past age 62. If the answer to this question $(\mathrm{P}(62))$ is zero, $\mathrm{P}(65)$ is assigned a value of zero as well. Respondents are not asked $\mathrm{P}(62)$ and $\mathrm{P}(65)$ if they are 62 or older. ${ }^{9}$ We will focus on the effect of the repeal of the earnings test after NRA on $\mathrm{P}(65)$, but will also consider its potential effects on $\mathrm{P}(62)$. We expect smaller effects here than for $\mathrm{P}(65)$, but it may be the case that respondents who change their mind about working at age 65 are more likely to keep working between age 62 and age 65, due to the costs of labor force exit and entry.

\footnotetext{
${ }^{9}$ There are some exceptions due to routing inconsistencies.
} 
The third expectations question we consider is the expected age at which respondents expect to claim Social Security benefits. We will denote this variable as EC. Values are missing for respondents who reported they did not anticipate receiving any Social Security benefits. There is a fair amount of don't knows as well. Overall, the value is missing for $19-24 \%$ of the respondents in our sample (varying across waves). Note that $\mathrm{EC}$ is just a point estimate, if respondents are uncertain it may be the most likely age at which they think they can start claiming, or the median or mean of their subjective distribution. Thus the information in this point estimate is more ambiguous than the information in the probability questions $\mathrm{P}(62)$ and $\mathrm{P}(65)$ (cf. Manski, 2004).

Table 5 shows the evolution of expectations over time. Answers to $\mathrm{P}(65)$ and EC show an upward trend over time in this sample. Of course, we do not know if this is a true time effect because the composition of the sample changes over waves. This is a consequence of the age restriction - only respondents younger than 62 . This age restriction is needed for $\mathrm{P}(62)$ and $\mathrm{P}(65)$ because these questions are not asked after that, and is also used for the expected claiming age to avoid dealing with the sample selection problem introduced by those who start claiming from age 62. Furthermore, because refreshments come into the sample in 1998 and 2004, any differences across cohorts that are not caused by the repeal, will show up in the aggregate time trend also. Fortunately, the longitudinal nature of our data allows us to control for such changes in the composition over time (see section 5).

\section{Calculation of Incentive Measures from the Earnings Test}

Since we can calculate social security benefits and potential loss due to the earnings test for respondents with a match, we can calculate various measures of social security wealth that involve the effect of the earnings test at the early retirement age (62) and the normal retirement age (65 or 66$)$. We consider three such measures:

A. Myopic loss: In the year where earnings are above the maximum allowed, the loss is given by

$$
e_{k}=\max \left(\min \left(\tau_{k}\left[w h-E_{k}\right], P_{1}\right), 0\right), k=E R A, N R A
$$

It is the loss in benefit that the worker incurs if he earns $w h$ at age $k$. 
B. Forward-Looking Loss according to life-table survival Probabilities: This measure is the sum of the myopic loss and the gain arising from the actuarial adjustment compared to a situation where there is no earnings test,

$$
f_{L, k}=e_{k}-\sum_{s=k}^{A} S_{L, k}(s) \theta^{s-k+1}\left(\pi_{k} \delta_{k} P_{k, s}\right)
$$

where $S_{L, k}(s)$ represents the life-table probability of living to age $s$ given survival up to age $k$. The terminal age $A$ is set such that $S_{L, k}(A) \approx 0$ (here $A=109$ ). $P_{k, s}$ is the pension someone gets at age $s$ from claiming at age $k$.

C. Forward-Looking Loss according to subjective survival probabilities: As discussed by Tran (2004), the actuarial adjustment may be fair for some but not for others who have lower life expectancy. This is particularly important in the case of the earnings test since individuals who are at the kink (the point where the earnings test kicks in), are likely to have lower socio-economic status and health than those high in the earnings distribution. One reason why the earnings test might have an effect on those workers is that the actuarial adjustment is relatively unfair for them. We also consider a forward-looking loss measure that takes account of the dispersion in survival probabilities in the population. Delavande and Rohwedder (2006) find that the heterogeneity in subjective probabilities proxies very closely the variation in true survival probabilities in the HRS/AHEAD panel. We therefore construct a set of probabilities $S_{j, k}(s)$ for groups of respondents characterized by health, education, gender and age (see section 4.2 for details). Essentially, the life-table survival profile is adjusted for variation in subjective survival across these cells. The subjective loss is given by

$$
f_{j, k}=e_{k}-\sum_{s=k}^{A} S_{j, k}(s) \theta^{s-k+1}\left(\pi_{k} \delta_{k} P_{k}\right) .
$$

Note that (6) and (7) are not exactly correct in the case where we evaluate the loss at the early retirement age. In that case, the actuarial adjustment only kicks in once the worker reaches the NRA. One way to incorporate that is to define $\pi_{E R A, S}=I(s \geq N R A) \pi_{E R A}$ so that the actuarial adjustment in the earnings test operates only after the NRA.

For forward looking measures, we use a real discount rate of 3\% (i.e., $\theta=0.97$ ).

We use a $2.9 \%$ inflation rate in our forecast. Thus the nominal discount rate we use is $5.9 \%$. 


\subsection{Calculation of Benefits}

We calculate the AIME of each respondent for each year in the survey as well as the projected AIME from ages 62 to 69. As for growth in future earnings, we use the growth in the Average National Wage Index. We take the last Social Security earnings in the SS.Er as the basis for computing each projection. This also assumes that the worker continues to work until the age at which we calculate the AIME. Hence, we adjust quarters of coverage accordingly so that an individual who is not eligible at age 55 but works until 62 could become eligible at age 62 . In general workers are eligible if they accumulated more than 40 quarters of coverage (10 years where they accumulated 4 credits from covered earnings). To calculate benefits, we use a formula constructed from the Social Security Handbook. We have done limited benchmark against the Social Security ANYPIA formula. Many parameters of the benefit formula are adjusted every year by SSA to reflect general changes in prices and cost-of-living. For years beyond 2004, parameters of the formula such as bend points for computing the PIA, the exempt amount under the Earnings test, the maximum taxable earnings for Social Security are all updated using their average growth rate over the period 1985-2003. This is usually closely in line with the average national wage index. Hence, this implies that workers expect a change in those parameters which is consistent with previous recent changes to the benefit formula.

In the formula, we do not implement dependent benefits. The earnings test become much more complicated for those receiving spouse benefits (their benefit depends on their as well as their spouse's behavior). Hence, we calculate only benefits available under the respondent's earnings record. This approximation is likely to be very close to actual benefits for men but perhaps different for females who draw spouse benefits. We take into account the minimum PIA in case the worker's PIA is too low. Upon calculating the PIA, the benefit is adjusted for early or late claiming using the Actuarial Reduction factor (ARF before NRA) and the Delayed Retirement Credit (DRC) that applies depending on the birth cohort. We implement the COLA adjustment which adjusts for inflation and cost-of-living increases. The average cost-of-living adjustment over the period 1985-2003 is used (2.9\%). Finally, the earnings test is implemented using the rules in effect as outlined in Table 1. 


\subsection{Survival Probabilities}

\section{Using life tables}

To operationalize our adjustment of life-table survival probabilities, we start from a simple exponential hazard model widely used to approximate survival curves, the Gompertz hazard. We assume that life table mortality rates follow the specification $m_{L}(a)=\kappa_{0, L} \exp \left(\kappa_{1, L} a\right)$, where $a$ is age and the parameters $\kappa_{0, L}$ and $\kappa_{1, L}$ control the level

and the slope of the $\log$ mortality rate. $\operatorname{Using} S_{L}(a)=\exp \left(-\int_{0}^{a} m_{L}(s) d s\right)$, the probability to survive until at least age $a$ is given by

$$
S_{L}(a)=\exp \left[\frac{\kappa_{0, L}}{\kappa_{1, L}}\left(1-\exp \left(\kappa_{1, L} a\right)\right)\right] .
$$

Conditional on surviving up to age $a$, an individual has a probability to survive up to age $s(s>a)$ given by $S_{L, a}(s)=S_{L}(s) / S_{L}(a)$.

\section{Using subjective probabilities}

The HRS asks age eligible respondents to report the probability they will survive up to age 75. Answers to such questions are known to include considerable measurement error, as well as focal responses (at 0,50 and 100). Hence, estimation of individual survival curves is difficult (see Gan, Hurd and McFadden, 2003). We therefore prefer to estimate group level subjective survival curves. We define groups by age ( 2 year age categories), education level (less than $12 \mathrm{yrs}, 12 \mathrm{yrs}$, more than $12 \mathrm{yrs}$ ) and health status (excellent/very good/good or fair/poor). We pool all waves (ignoring calendar time effects) and calculate the mean of the subjective probability responses within each ageeducation-health cell. Hence, a respondent's cell and reference subjective life-table can change over waves if the respondent changes group, e.g. due to deterioration of health or simply due to aging.

In terms of the Gompertz model, the answers to the subjective probability question from age $a$ to age 75 represent a point on the conditional subjective survival curve of group $j$,

$$
S_{j, a}(75)=\frac{\exp \left[\frac{\kappa_{0, j}}{\kappa_{1, j}}\left(1-\exp \left(\kappa_{1, j} 75\right)\right)\right]}{\exp \left[\frac{\kappa_{0, j}}{\kappa_{1, j}}\left(1-\exp \left(\kappa_{1, j} a\right)\right)\right]}
$$


We impose that the baseline hazard across all groups is the same as the baseline hazard of the life-table $\left(\kappa_{1, j}=\kappa_{1, L}\right)$. This means we estimate the proportional change in the mortality hazard across groups but not the baseline hazard. The shape could be estimated using the probability question to age 85 or using the fact that the conditional survival curve is observed at different ages (from age 51 to 61). However, an analytical solution is difficult to obtain for the two parameters simultaneously.

We can estimate $\kappa_{0, L}, \kappa_{1, L}$ from the life table mortality rates. We do this separately for men and women and for each year in the survey, using the yearly life-tables available at www.mortality.org (based on Vital Statistics). We regress $\log \left(m_{L}(a)\right)=\log \left(\kappa_{0, L}\right)+\kappa_{1, L} a+u$ where $u$ is an error term. Define the log ratio of the conditional survival probabilities to age $s$ from age $a$ as

$$
r_{j, a}(s)=\log \left[\frac{S_{j, a}(s)}{S_{L, a}(s)}\right]=\left(D_{L}(s)-D_{L}(a)\right)\left[\kappa_{0, j}-\kappa_{0, L}\right],
$$

where

$$
D_{L}(x)=\exp \left(\frac{1}{\kappa_{1, L}}\left(1-\exp \left(\kappa_{1, L} x\right)\right)\right)
$$

This last term is "known" from estimation of the life-table parameters of the mortality hazard.

The proportional constant for group $j$ is then given by

$$
\kappa_{0, j}=\frac{r_{j, a}(s)}{d_{L}(s)-d_{L}(a)}+\kappa_{0, L},
$$

where $d_{L}(x)=\log \left(D_{L}(x)\right)$.

The conditional subjective survival at each age for group $j$ can be calculated from (9). These "corrections" adjust only for differences in the level of the log mortality hazard. Since this is probably the predominant difference in the underlying true hazard, this is likely to capture a considerable amount of differential mortality across groups.

Table 6 reports the distribution of survival probabilities for 55 year old male and female respondents in 1992. The table shows that there is serious underprediction of survival probabilities to age 75, particularly for females (cf. Hurd and McGarry, 1995). For males, underprediction is rather small (3\%), compared to $12 \%$ for females. 


\subsection{Incentive Measures: Is the Earnings Test a Tax?}

We first describe patterns of expected social security wealth assuming workers retire when they claim Social Security benefits. This helps understand the heterogeneity in the actuarial adjustment which workers face when they consider claiming benefits. We compute Social Security wealth as

$$
\begin{aligned}
& W_{L, k}=\sum_{s=k}^{A} S_{L, k}(s) \theta^{s-k} P_{k, s} \\
& W_{j, k}=\sum_{s=k}^{A} S_{j, k}(s) \theta^{s-k} P_{k, s} \\
& k=62, \ldots, 69
\end{aligned}
$$

Here $P_{k, s}$ is the annual social security benefit that we project the respondent could get at age $s$ if starting to claim at age $k$. In addition to this measure, we compute an "accrual" rate defined as

$$
\begin{aligned}
& A_{L, k}=\frac{W_{L, k+1}-W_{L, k}}{W_{L, k}}, \\
& k=62, . ., 68
\end{aligned}
$$

Similarly, we compute accrual rates $A_{j, k}$ using subjective mortality rates instead of life tables. If the accrual rate is zero, this means that the actuarial adjustment is perceived as fair from the point of view of the worker (given the assumptions on the survival probabilities and the discount rate). If it is negative, the worker loses in terms of expected social security wealth if he delays claiming. Because workers differ in terms of their potential benefits, earnings history, birth cohort (which determines many benefit rule parameters), and life expectancy (in the subjective case), there is considerable variation in the accruals.

Table 7 presents Expected Social security wealth at age 62, the early retirement age, for the $10^{\text {th }}, 25^{\text {th }}, 50^{\text {th }}$ (Median), $75^{\text {th }}$ and $90^{\text {th }}$ quantile of the sample of workers aged 51-61. It also reports the ratios of these quantiles to the median and the distribution of accruals defined in equation (14). This is done using both life-table probabilities and the adjusted mortality probabilities in equation (9).

Using life-table probabilities, median expected social security wealth at age 62 is $\$ 148,000$. There is considerable variance, with the $10^{\text {th }}$ quantile expecting $\$ 58,000(0.39$ 
times the median) and the $90^{\text {th }}$ quantile expecting $\$ 228,000$ (1.54 times the median). Hence, simply in terms of income effect, workers differ in their incentives to claim benefits as early as possible. The variance is larger when using subjective based survival rates. The median using subjective survival probabilities is lower $(\$ 147,000)$ which reflects higher pessimism in the subjective survival probabilities of workers, on average The ratio of the $10^{\text {th }}$ and $90^{\text {th }}$ quantile to the median ( 0.38 and 1.67 respectively) reflect somewhat higher variance than when using life-table probabilities, which can be explained by the heterogeneity in subjective survival probabilities.

Social Security accruals are generally positive at the median until age 65 where for some workers, the DRC may not be sufficient to compensate for increased mortality risk. There is also considerable heterogeneity in accruals. For example, at age 65, half of the sample has a negative accrual while the other half has a positive accrual. Accruals tend to be lower in general using subjective probabilities because of higher aggregate mortality risk. But again the distribution is more dispersed than when using life-table accruals. At age 65 , the $90^{\text {th }}$ quantile faces a $2.47 \%$ accrual if he delays claiming to age 66 , compared to $2.0 \%$ when using the life-table.

The median accrual decreases with age. It is interesting to note that the difference between subjective and life-table accruals is largest in the right tail of the distribution (i.e. for workers with high accruals). For these workers, life-table probabilities lead to considerable "overestimation" of the accrual, as revealed by their subjective probabilities of survival. The actuarial adjustment is at the center of the question as to whether the earnings test is a tax or not. Table 7 shows that this adjustment is likely to be perceived as unfair by a large fraction of the population around the normal retirement age.

In Table 8, we compute the loss (or gain) due to the earnings test using the myopic loss $e_{k}$, the forward-looking measure using life-table survival probabilities $f_{L, k}$ and using subjective survival probabilities $f_{j, k}$. These losses are reported in dollars, as a fraction of earnings, and as a fraction of liquid financial assets (as a measure of liquidity constraints). The myopic loss is larger at age 62 than at the NRA. This is due to a higher exempt amount at the NRA and a lower marginal tax rate. The heterogeneity in myopic tax rates is largely due to differences in projected earnings as well as differences in benefit entitlements. 
Because of actuarial adjustments, the forward looking tax is much lower than the myopic rate. Of course, if the actuarial adjustment was perceived as completely fair, there would be no such tax. Additional heterogeneity is introduced when computing these forward-looking taxes. These now vary by birth cohort (due to different actuarial adjustment) and other differences entering the survival probabilities. The subjective forward-looking tax measure is somewhat higher for females than for males. This is because females underpredict their probability to live up to age 75 .

Since one interpretation why workers might prefer to claim and be subject to the earnings test is that they are liquidity constrained, we express these same taxes as a fraction of current liquid wealth. This shows that for most workers, the tax due to the earnings test is relatively small. But for a fraction of workers, the tax actually represents a large fraction of their liquid wealth

Because actuarial adjustments and the normal retirement age change across cohorts, there is considerable heterogeneity in incentives across cohorts. Table 9 gives the median of the various tax variables by birth year. These numbers help understand why the earnings test will have different effects across different cohorts. For those born in 1932, the forward-looking tax is much larger than for those born latter. This can be explained by the lower delayed retirement credit faced by those workers. For the workers that will be affected by the earnings test in 2000 , born in 1935, the delayed retirement credit was $6.0 \%$ (see Table 1), leading to tax rates that are relatively low.

The mean forward looking tax rate is very close to zero for younger workers. About $90 \%$ of workers in the age 51-61 sample face a tax lower than $\$ 5000$ on life-time Social Security wealth. Expressed as a fraction of earnings or financial wealth, the tax imposed by the earnings test is therefore not large. Hence, if workers perceive the rules correctly, we should not expect them to react significantly to the repeal. This response is even less likely for workers born in latter cohorts, for whom the rate of actuarial adjustment is larger.

\section{The Effect of the Repeal on Expectations}

As explained in Section 2, workers with different expected loss due to the earnings test are predicted to react differently to the repeal. This is the case if workers are not aware of the actuarial adjustment compensating for benefits lost due to the earnings test, or, to a lesser extent, to workers who perceive the actuarial adjustment as actuarially 
unfair. This suggests that we can use a difference-in-difference approach by grouping workers according to the pre-repeal incentives they faced as a consequence of the earnings test. The key to this identification strategy is the determination of the groups that get different treatments. We define the groups based on the percentage of social security benefits predicted to be lost at the normal retirement age (NRA).

For example, those who were not expected to be affected by the repeal, i.e. had no loss due to the earnings test, are not likely to react to its repeal. This concerns everyone with earnings below the exempt amount. On the other hand, those who earn exactly the exempt amount or somewhat more should react to the repeal - it will increase the marginal return to working more hours, and we therefore expect them to get a higher probability to work full-time past age 65. For the group who earn substantially more than the exempt for whom a high share of their benefit but not everything is taxed away, the same substitution effect applies, but this is more likely to be compensated by an income effect: eliminating the earnings test will not only change their marginal wage but also bring them to a higher indifference curve. This effect will become larger the higher the amount of benefit which was lost under the earnings test. Hence, for the group that has a substantial fraction taxed away, the total effect is unknown. Finally, for the group for whom all benefits are taxed away under the earnings test, there will be no substitution effect but only a (probably negative) income effect, and one would expect a negative effect of eliminating the earnings test on the probability to work past 65 .

We thus define groups in the following way:

1. No benefit lost: Projected earnings below $80 \%$ of the exempt amount,

2. $1 \%$ to $49 \%$ of benefit lost

3. $50 \%$ to $99 \%$ of benefit lost

4. $100 \%$ of benefit lost

Denote by $g_{c}, c=1,2,3,4$, the indicators that take value 1 when the respondent is in one of these four groups. We use 1998 as the year to define the grouping since it is the wave preceding the repeal. Define a variable $R E P_{t}$ that takes value 1 for observations after the repeal in 2000. Since job characteristics are only observed from 1996 onwards, and we 
cannot use the cohort of "Early boomers" in 2004, and we are left with the time widow 1996-2002.

We first consider the respondents who report a non-missing expectation in waves 1998 and 2002. The idea is to look for a differential change between the two waves across groups. Composition effects cannot occur because we consider the same respondents in both waves. The identifying assumption is that all groups would have similar trends in expectations if there were no repeal. Table 10 reports mean expectations in both waves for each group, separately for males (left hand panel) and females (right hand panel).

For males, the results for $\mathrm{P}(65)$, the probability to work full-time at any point in time after reaching age 65 , are in line with what the theory discussed above predicts. Respondents for whom the earnings test was not binding (group 1) hardly change their average $\mathrm{P}(65)$, and the fraction with nonzero $\mathrm{P}(65)$ does not change much either. This suggests that there is not much of a trend in $\mathrm{P}(65)$. For group 2, the group for which we predicted the largest positive effect, we indeed find a substantial increase in the average value of the probability to work full-time after the normal retirement age of 65 years, and we also find a substantial increase in the fraction reporting that this probability is nonzero. Taking group 1 as the control group (the group with no treatment), the difference in differences estimators are $2.98 \%$-points for the increase in the average $\mathrm{P}(65)$ and $7.75 \%$-points for the increase in the percentage of male workers with nonzero $\mathrm{P}(65)$. For group 3, we find positive but smaller effects, in line with theory - here the positive substitution effect is partly cancelled by a negative income effect. Finally, for group 4, we do not find much of an effect. We would have expected to find a negative income effect here, but their change in $\mathrm{P}(65)$ is actually somewhat larger than that for the control group instead of smaller. For these workers, Social Security benefits may actually represent a small share of their total wealth.

For female workers, the effects are quite different. All groups have positive changes, including the control group, suggesting a positive trend in the probability to work full-time past age 65 for these cohorts. The three groups that are affected by the earnings test (and its elimination) all show larger positive effects than the control group, implying that elimination of the earnings test will have a positive effect on labor supply. In contrast to the theoretical prediction and the results for men, however, the effect is small for group 2 and larger for groups 3 and 4 . An explanation may be that for women, 
spouse benefits play a large role, and their importance will correlate with their own group assignment (because of joint features in earnings capacity and labor supply of couples). Spouse benefits are not accounted for in our analysis. We therefore do not want to make much of the results for females.

In the bottom panel of Table 10, we consider the expected age at which respondents think they will start claiming old age social security benefits. If people would think they are heavily taxed by the earnings test (ignoring or downgrading the compensation in the form of actuarial adjustment), but would realize that claiming later leads to higher benefits, we would expect that abolishing the earnings test has positive effects on the probability to claim at (or before) the normal retirement age. These effects should be largest for the people who are taxed most, i.e., for groups 3 and 4. On the other hand, if labor supply increases due to elimination of the earnings test, people will be less in need of immediate benefits and will tend to postpone claiming. This gives a negative effect on the probability to claim at NRA, particularly for group 2 and to a lesser extent for group 3. The results show that for all groups the probability to postpone claiming till after NRA rises over time, but the change is largest for group 1, the group that is unaffected by the earnings test. Thus abolishing the earnings test seems to make people claim earlier, in line with the first effect discussed above - their earnings are no longer taxed away. The differences between the three groups, however, are not in line with the theoretical arguments, neither for men nor for women.

An alternative interpretation would be that many workers also do not understand the negative consequences of early claiming for their future benefits level. Many workers will simply anticipate that they will start claiming when they stop working. Again, however, this is not in line with the results - we would then expect the largest positive effect on the probability to postpone claiming for group 2, the group with the largest positive effect on labor supply after NRA.

The difference in differences estimator only consider the balanced sample of individuals who work and answer the expectations questions both in 1998 and 2002. In order to exploit the complete unbalanced sample, we formulate a model that also controls for several background characteristics.

We observe for each individual $i$ in wave $t=1, \ldots, T_{i}$, the subjective probability to work past age $65, p_{i t}$, and the age at which respondents expect to claim benefits $e_{i t}$. We 
model $p_{i t}$ with a two-limit tobit equation, accounting for the substantial number of zeros and 100 in the observed answers:

$$
\begin{gathered}
p_{i t}^{*}=\alpha_{0}+\alpha_{1} g_{i 1}+\alpha_{2} g_{i 2}+\alpha_{3} g_{i 3}+\lambda_{t}+x_{i t} \delta+\sum_{c=1}^{3} \xi_{c}\left(R E P_{t} \times g_{i c}\right)+u_{i t} \\
p_{i t}=\min \left[\max \left(0, p_{i t}^{*}\right), 100\right] \\
i=1, \ldots, N, t=1, \ldots, T_{i}
\end{gathered}
$$

We consider two specifications, one where the $u_{i t}$ are assumed to be independent over time (pooled tobit) and one where the $u_{i t}$ are equi-correlated, i.e., are the sum of an error term which is assumed to be independent over time, and an individual effect which remains the same over time.

We include dummies for three of the four groups to capture differences between groups that remain constant over time, and time dummies to capture the trend relevant for all groups. (These variables were also included in the model which implicitly was behind the difference in difference estimates presented in Table 10). We also incorporate a number of background characteristics, some constant over time (race and education), others time varying (health, job characteristics, pension entitlements, household wealth).

The left hand panels of Tables $11 \mathrm{a}$ and $11 \mathrm{~b}$ report the estimates of the parameters of main interest, the interactions $\left(\xi_{c}\right)$ which measure the differential effect of elimination of the earnings test for each of the four groups. The complete two-limit tobit results (and the details on which background variables are included) are presented in the appendix.

There are some differences in size of coefficients between the two columns, but qualitative conclusions are largely similar. The findings for men are largely in line with the difference in differences estimates in Table 10. We find results in accordance with theory - the largest positive effects of eliminating the earnings test are found for those whose marginal wage increases, a positive substitution effect. Unlike in Table 10, however, there is no evidence that an income effect in the opposite direction would reduce the total change for those with a substantial income gain (group 3). The estimated effect for group 3 is actually somewhat larger than that for group 2, though not significantly so. Evidence of an income effect is also not apparent from group 4 - its reaction to the elimination is not significantly different from that of the control group. 
For women, the sign and ordering of the effects are in line with theory, with group 2 having the largest positive (substitution) effect, a smaller positive effect for group 3 , and a negative (income) effect for group 4. None of these effects are significant, however.

In column 3, we consider the binary event whether a worker reports a positive or a zero probability to work full-time after age 65 . A random effects probit model is used, with a specification that is otherwise the same as the random effects tobit model in the second column. The results for men are more in line with the theory than those for the tobit models, in the sense that group 2 now is affected most by elimination of the earnings test. The effect for group 3 is positive also, but smaller and not significant. For women, the results are qualitatively similar to those for the tobit models. The effects have the sign and ranking predicted by theory, but none of them is significant.

We also considered $\mathrm{P}(62)$, the probability of working past age 62 . We have estimated the same models for this as for $\mathrm{P}(65)$, but found that the repeal of the earnings test had a small and insignificant effect for all groups. See the Appendix for the results. This is understandable - although there are reasons why there could be indirect labor supply effects of the earnings test on $\mathrm{P}(62)$, the effects are likely to be smaller than those on $\mathrm{P}(65)$ where within period is immediately affected. The fact that we do not find evidence of these effects could be seen as evidence against intertemporal substitution or life-cycle optimization, but it could also just mean that these indirect effects are too small to be significant in the available sample.

Columns 4 and 5 of Tables 11a and 11b present the estimates of the effect of elimination of the earnings test on the expected claiming age. Column 4 presents the results of a random effects ordered probit model, distinguishing three cases: claiming before NRA, claiming at NRA, or claiming after NRA. A positive coefficient indicates that the probability to claim before NRA falls while the probability to claim after NRA rises (the effect on claiming at NRA is ambiguous). In column 5, no distinction is made between claiming before or at the normal retirement age, and a random effects probit model is estimated. The right hand sides of the ordered probit and probit models are specified in the same way as in the models for $\mathrm{P}(65)$.

In line with the results in Table 10, the parameter estimates are small, and we do not find significant effects on the expected claiming age. Only if the three groups that are affected by the earnings test are merged (top panel of the table), we find marginally 
significant effect for men and a significant effect in the ordered probit for women, but the signs of the effects are opposite in the ordered probit and the probit model.

\section{Deviations from Expectations}

In the previous section we found that the repeal of the earnings test after NRA has had an effect on the probability that male respondents will work after age 65 , but we found no evidence on an effect on the expected claiming age. One possible explanation for the latter might be that respondents report their most likely retirement age and the effect of the repeal may not be large enough to change this, even though the repeal does have an effect on the probability distribution. In this sense, the expected claiming age is not so informative. In this section we look at the realized claiming age, which does not suffer from the same problem - it is a realization, not a forecast. We consider two indicators of actual claiming decisions: whether someone claims when reaching NRA (or earlier), and the difference between the age when someone starts claiming and the last available forecast (given at age 61 or earlier).

For the actual decisions when respondents start claiming Social Security benefits, we select the survey years 1998 and 2000 and look at respondents who reach NRA between these two waves, who have not yet claimed Social Security benefits in 1998, and who will eventually claim prior to age $70 .^{10}$

Table 12 presents the results. The number of respondents who claim immediately after reaching NRA increases with the repeal of the earnings test. The increase is substantial for men (13.7\%-points), and smaller for women (3.7\%-points). On the other hand, as we saw earlier, the expected claiming age does not show the same reaction to the repeal. As a consequence, we find that the average difference between actual and expected claiming age has become negative in 2000, while it was almost zero in 1998, for both men and women.

The bottom panel distinguishes the same four groups as before, on the basis of how much their earnings are taxed while the earnings test is still in place. Men and

\footnotetext{
${ }^{10}$ For those reaching the NRA in 2000, we observe whether they claim at age 69 or earlier in the 2004 wave. Hence, to avoid problems of right-censoring, we select the sample of those who will actually claim between 65 and 69 years old. We consider 2000 rather than the 2002 interview because of this censoring issue. In 1996, very few respondents have reached the NRA. Only the oldest of the original cohort (age 61 in 1992). This is why we start in 1998.
} 
women have been merged to increase sample size. Still, sample size is quite small and the results should be interpreted with some care - differences are not statistically significant at the usual levels. Still, the results suggest that particularly those who were most affected by the earnings test decide to claim earlier after the earnings test is repealed. The groups with tax rates higher than $50 \%$ are the groups for which the difference between actual and expected claiming age is less (i.e., less positive or more negative) in 2000 than in 1998. The increase in the fraction of people claiming immediately after NRA is largest for the group with the highest tax on their SS benefits under the earnings test (27\%-points), and the differences are also positive but smaller for the other groups who are taxed.

While suffering from small sample size, all these results thus point in the same direction: the repeal of the earnings has induced a change in actual claiming behavior that is in line with economic theory - more people claim immediately upon reaching NRA, because their benefits are no longer taxed by the earnings test. This leaves us with the question why we do not find an effect on expected claiming age, while the results for $\mathrm{P}(65)$ suggest that (male) respondents do adjust their expected labor supply behavior. A possible answer is that the expected claiming age provides incomplete information on the respondents' subjective probability distribution. It may well reflect the most likely outcome only, and probabilities may change without changing this most likely outcome.

\section{Conclusions}

The elimination of the earnings test on social security benefits after the normal retirement age has been used as a natural experiment in various studies on actual labor supply at an older age. In this study, we have focused on how this policy changes affects expectations of workers who have not yet reached an age at which they can claim old age

social security benefits. We have presented a two period theoretical model, demonstrating that workers should react in different ways, depending on where they are on their budget set while the earnings test is still in place. This model also implies that the effects are smaller if workers realize that taxed away benefits will be returned in later years with actuarial adjustment. In that case, depending on the individual's discount factor and the actuarial adjustment rate, it may even be the case that the earnings test is irrelevant.

The advantage of looking at expectations is that we can see how expectations of the same people develop over time. Moreover, since some groups were not affected by 
the earnings test in the first place, a control group is available. Administrative social security records linked to the core HRS data allow us to distinguish the control group and several treatment groups in our data. Combining this with the time dimension allows for a difference in differences approach. We applied this both to the self-reported probability of working full-time after age 65 (the normal retirement age during the time period we consider), and to the self-reported expected claiming age.

For men, we find substantial effects of elimination of the earnings test that on the probability to work after the normal retirement age, and the qualitative effects are in line with the theoretical predictions under the assumption that people do not realize that benefits taxed away by the earnings test are returned later with actuarial adjustment, or under the assumption that people have large discount rates or face liquidity constraints so that they hardly account for the future consequences of their current decisions. For women, no clear effects of elimination of the earnings test are found, probably due to the relation between the effect of the earnings test on own benefits and changes in spousal benefits, relevant to a large fraction of women in the sample. The issue of spouse benefits is not dealt with in the current paper and is an issue of further research.

Neither for men, nor for women, significant effects on the expected claiming age are found. This is puzzling, since theoretical arguments would predict that effects on labor supply and retirement would be accompanied by changes in the expected claiming age. It casts some doubt on whether people choose their (expected) claiming age based on the economic trade-off between leisure and income. This is also an issue for further research.

The conclusion that people adjust their future work and retirement plans to the rules of the social security system is important for public policy. It also implies that people realize that the rules change, giving them at least a chance to reconsider their retirement savings and investment portfolio. On the other hand, the result that the adjustment of plans is largely based on misperception of the rules, ignoring the actuarial adjusted compensation in later years for benefits lost under the earnings test, is also relevant. It confirms that many people do not always base their expectations and decisions on fully rational economic optimization and suggests that providing information and keeping the rules simple and transparent is as important in formulating policy measures as incorporating the desired financial incentives. 


\section{References}

Benitez-Silva, H. and F. Heiland (2005): The Social Security earnings test revisited: misinformation, distortions, and costs, mimeo, SUNY-Stony Brook.

Chan, S and A. Stevens (2004): Do changes in pension incentives affect retirement: a longitudinal study of subjective retirement expectations, Journal of Public Economics, 88, 1307-1333.

Delavande, A. and S. Rohwedder (2006): Differential mortality in Europe and the US: Estimates based on subjective probabilities of survival, mimeo, RAND.

Disney, R. and S. Smith (2001): The labour supply effect of the abolition of the earnings rule for older workers in the United Kingdom, Economic Journal, 112, C136-C152.

Friedberg, L. (2000): The labor supply effects of the social security earnings test, The Review of Economics and Statistics, 82(1), 48-63.

Gan, L., Hurd, M.D., and D. McFadden (2003): Individual subjective survival curves, NBER Working paper 9480.

Gruber, J. and P. Orszag. (2003). Does the Social Security earnings test affect labor supply and benefits Receipt? National Tax Journal, 56(4), 755-773.

Gustman, A. and T. Steinmeier (2004): The Social Security retirement earnings test, retirement and benefit claiming, NBER Working Paper 10905, Cambridge, MA: National Bureau of Economic Research.

Haider, S. and D.S. Loughran (2005): Do the elderly respond to taxes on earnings? evidence from the Social Security retirement earnings test, Labor and Population Working Paper WR-223, Santa Monica: RAND.

Hurd, M. and K. McGarry (1995): Evaluation of the subjective probabilities of survival in the HRS" Journal of Human Resources, 30, S268-S292.

Hurd, M. (1996): The effect of labor market rigidities on the labor force behavior of older workers, in Advances in the Economics of Aging, D. Wise (ed.), University of Chicago Press, Chicago.

Hurd, M. (1999): Labor market transitions in the HRS: effects of the subjective probability of retirement and of pension eligibility, in James P. Smith and Robert J. Willis (eds.), Wealth, Work and Health, University of Michigan Press, 267-290.

Leonesio, M.V. (1990): The effects of the Social Security earnings test on the labormarket activity of older Americans: a review of the empirical evidence, Social Security Bulletin, 53(5), 2-21. 
Manski, C. (2004): Measuring expectations. Econometrica, 72, 1329-1376.

Tran, Bac V. (2004): The impact of the repeal of the retirement earnings test on the labor supply of older workers, mimeo, University of Maryland.

\section{Figures}

\section{Figure 1 Expected Income, Claiming and First Period Hours of Work (Leisure)}

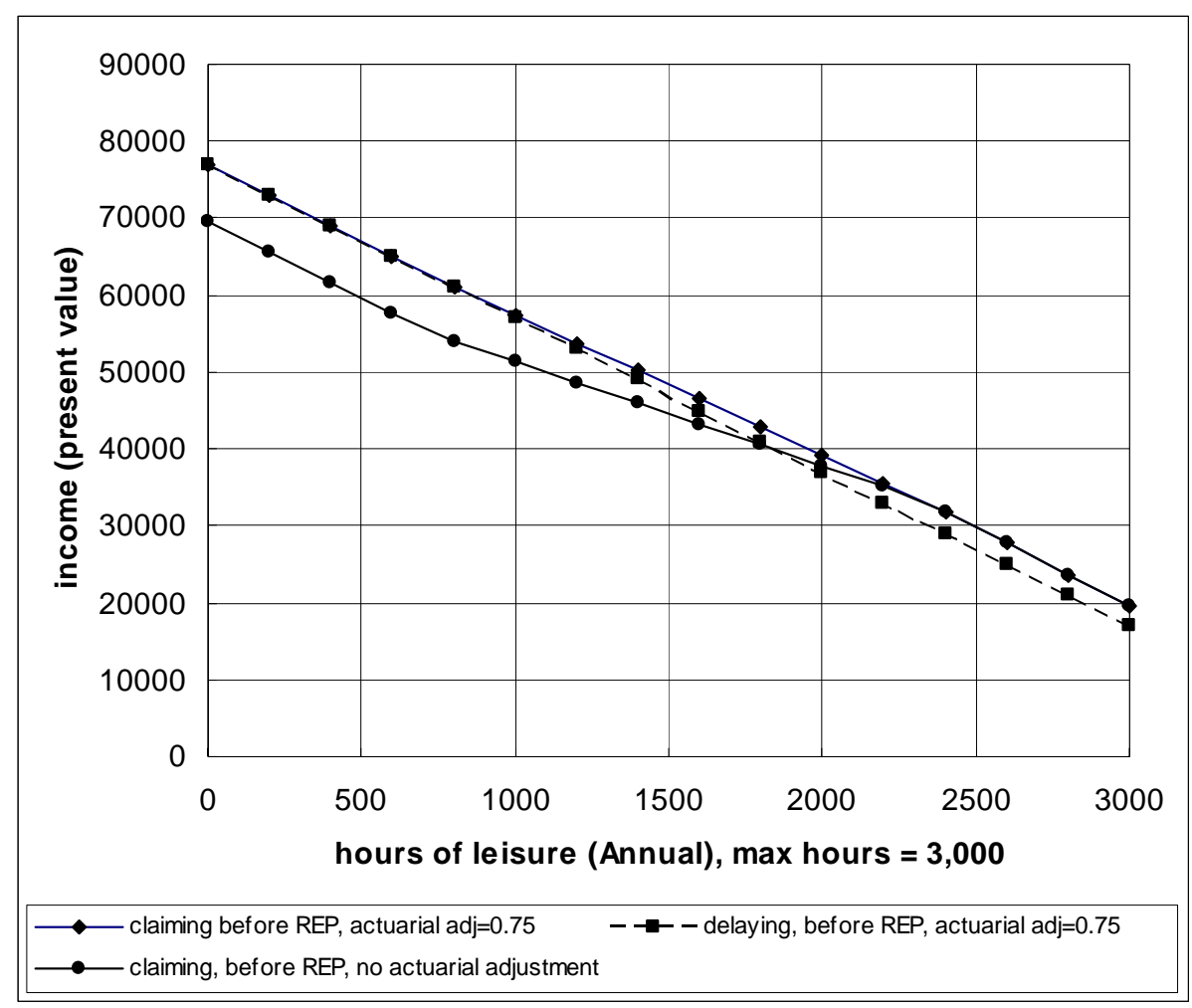


Tables

Table 1 Parameters of the Earnings Test and Actuarial Adjustment 1992-2004

\begin{tabular}{|c|c|c|c|c|c|c|c|}
\hline for those reaching the NRA in & 19992 & 1999 & 19996 & 19998 & 2000 & 2002 & $\overline{2004}$ \\
\hline NRA & 65 & 65 & 65 & 65 & 65 & 65 & $654 \mathrm{mo}$ \\
\hline Earnings Limit before NRA & 7,440 & 8,040 & 8,280 & 9,120 & 10,080 & 11,280 & 11,640 \\
\hline Earnings Limit after NRA & 10,200 & 11,160 & 12,500 & 14,500 & None & None & None \\
\hline Tax before NRA & $50 \%$ & $50 \%$ & $50 \%$ & $50 \%$ & $50 \%$ & $50 \%$ & $50 \%$ \\
\hline Tax after NRA & $33 \%$ & $33 \%$ & $33 \%$ & $33 \%$ & $0 \%$ & $0 \%$ & $0 \%$ \\
\hline $\begin{array}{l}\text { Actuarial Reduction Factor (before } \\
\text { NRA) }\end{array}$ & $6.8 \%$ & $6.8 \%$ & $6.8 \%$ & $6.8 \%$ & $6.8 \%$ & $6.8 \%$ & $6.8 \%$ \\
\hline $\begin{array}{l}\text { Delayed Retirement Credit (DRC) } \\
\text { (after NRA) }\end{array}$ & $4.0 \%$ & $4.5 \%$ & $5.0 \%$ & $5.5 \%$ & $6.0 \%$ & $6.5 \%$ & $7.0 \%$ \\
\hline
\end{tabular}

Notes: Earnings limit defined in rule $\$ 1803.2$ of the Social Security Handbook 2004. Normal retirement age defined in $\S 723.5$.

Delayed retirement credit $\$ 720.3$. $\$ 724.1$ defines the actuarial reduction factor.

Table 2 HRS design

\begin{tabular}{|c|c|c|c|c|c|c|c|c|c|c|}
\hline \multirow[b]{2}{*}{ Birth year } & \multirow[b]{2}{*}{ DRC } & \multirow[b]{2}{*}{ NRA } & \multicolumn{3}{|c|}{ "Pre-Repeal } & \multicolumn{3}{|c|}{ Post-Repeal } & \multirow[b]{2}{*}{2004} & \multirow[b]{2}{*}{ HRS cohort } \\
\hline & & & 1992 & 1994 & 1996 & 1998 & 2000 & 2002 & & \\
\hline 1918 & $3.50 \%$ & 65 & 74 & 76 & 78 & 80 & 82 & 84 & 86 & \multirow{6}{*}{ AHEAD } \\
\hline 1919 & $3.50 \%$ & 65 & 73 & 75 & 77 & 79 & 81 & 83 & 85 & \\
\hline 1920 & $3.50 \%$ & 65 & 72 & 74 & 76 & 78 & 80 & 82 & 84 & \\
\hline 1921 & $3.50 \%$ & 65 & 71 & 73 & 75 & 77 & 79 & 81 & 83 & \\
\hline 1922 & $3.50 \%$ & 65 & 70 & 72 & 74 & 76 & 78 & 80 & 82 & \\
\hline 1923 & $3.50 \%$ & 65 & 69 & 71 & 73 & 75 & 77 & 79 & 81 & \\
\hline 1924 & $3.50 \%$ & 65 & 68 & 70 & 72 & 74 & 76 & 78 & 80 & \multirow{7}{*}{$C O D A$} \\
\hline 1925 & $3.50 \%$ & 65 & 67 & 69 & 71 & 73 & 75 & 77 & 79 & \\
\hline 1926 & $3.50 \%$ & 65 & 66 & 68 & 70 & 72 & 74 & 76 & 78 & \\
\hline 1927 & $4.00 \%$ & 65 & 65 & 67 & 69 & 71 & 73 & 75 & 77 & \\
\hline 1928 & $4.00 \%$ & 65 & 64 & 66 & 68 & 70 & 72 & 74 & 76 & \\
\hline 1929 & $4.50 \%$ & 65 & 63 & 65 & 67 & 69 & 71 & 73 & 75 & \\
\hline 1930 & $4.50 \%$ & 65 & 62 & 64 & 66 & 68 & 70 & 72 & 74 & \\
\hline 1931 & $5.00 \%$ & 65 & 61 & 63 & 65 & 67 & 69 & 71 & 73 & \multirow{11}{*}{$H R S$} \\
\hline 1932 & $5.00 \%$ & 65 & 60 & 62 & 64 & 66 & 68 & 70 & 72 & \\
\hline 1933 & $5.50 \%$ & 65 & 59 & 61 & 63 & 65 & 67 & 69 & 71 & \\
\hline 1934 & $5.50 \%$ & 65 & 58 & 60 & 62 & 64 & 66 & 68 & 70 & \\
\hline 1935 & $6.00 \%$ & 65 & 57 & 59 & 61 & 63 & 65 & 67 & 69 & \\
\hline 1936 & $6.00 \%$ & 65 & 56 & 58 & 60 & 62 & 64 & 66 & 68 & \\
\hline 1937 & $6.50 \%$ & 65 & 55 & 57 & 59 & 61 & 63 & 65 & 67 & \\
\hline 1938 & $6.50 \%$ & 65.02 & 54 & 56 & 58 & 60 & 62 & 64 & 66 & \\
\hline 1939 & $7.00 \%$ & 65.04 & 53 & 55 & 57 & 59 & 61 & 63 & 65 & \\
\hline 1940 & $7.00 \%$ & 65.06 & 52 & 54 & 56 & 58 & 60 & 62 & 64 & \\
\hline 1941 & $7.50 \%$ & 65.08 & 51 & 53 & 55 & 57 & 59 & 61 & 63 & \\
\hline 1942 & $7.50 \%$ & 66 & 50 & 52 & 54 & 56 & 58 & 60 & 62 & \multirow{6}{*}{ War Babies } \\
\hline 1943 & $8.00 \%$ & 66 & 49 & 51 & 53 & 55 & 57 & 59 & 61 & \\
\hline 1944 & $8.00 \%$ & 66 & 48 & 50 & 52 & 54 & 56 & 58 & 60 & \\
\hline 1945 & $8.00 \%$ & 66 & 47 & 49 & 51 & 53 & 55 & 57 & 59 & \\
\hline 1946 & $8.00 \%$ & 66 & 46 & 48 & 50 & 52 & 54 & 56 & 58 & \\
\hline 1947 & $8.00 \%$ & 66 & 45 & 47 & 49 & 51 & 53 & 55 & 57 & \\
\hline 1948 & $8.00 \%$ & 66 & 44 & 46 & 48 & 50 & 52 & 54 & 56 & \multirow{7}{*}{$\begin{array}{c}\text { Early } \\
\text { Boomers }\end{array}$} \\
\hline 1949 & $8.00 \%$ & 66 & 43 & 45 & 47 & 49 & 51 & 53 & 55 & \\
\hline 1950 & $8.00 \%$ & 66 & 42 & 44 & 46 & 48 & 50 & 52 & 54 & \\
\hline 1951 & $8.00 \%$ & 66 & 41 & 43 & 45 & 47 & 49 & 51 & 53 & \\
\hline 1951 & $8.00 \%$ & 66 & 41 & 43 & 45 & 47 & 49 & 51 & 52 & \\
\hline 1952 & $8.00 \%$ & 66 & 40 & 42 & 44 & 46 & 48 & 50 & 51 & \\
\hline 1953 & $8.00 \%$ & 66 & 39 & 41 & 43 & 45 & 47 & 49 & 50 & \\
\hline
\end{tabular}


Table 3: Sample of Workers aged 51-61

\begin{tabular}{rrrrrrrrrrrrrrrr}
\hline \hline age & \multicolumn{4}{c}{1992} & \multicolumn{1}{c}{1994} & \multicolumn{2}{c}{1996} & \multicolumn{2}{c}{1998} & \multicolumn{2}{c}{2000} & \multicolumn{2}{c}{2002} & \multicolumn{2}{c}{2004} \\
& all & SS.Er & all & SS.Er & all & SS.Er & all & SS.Er & all & SS.Er & all & SS.Er & all & SS.Er \\
50 & 378 & 293 & 146 & 115 & 104 & 74 & 233 & 139 & 106 & 62 & 48 & 24 & 235 & 27 \\
51 & 708 & 555 & 212 & 169 & 109 & 72 & 418 & 234 & 136 & 69 & 56 & 30 & 408 & 23 \\
52 & 685 & 500 & 393 & 306 & 136 & 102 & 343 & 197 & 261 & 142 & 103 & 54 & 483 & 29 \\
53 & 704 & 520 & 641 & 500 & 199 & 163 & 346 & 201 & 400 & 227 & 119 & 56 & 417 & 25 \\
54 & 622 & 466 & 600 & 456 & 373 & 286 & 359 & 227 & 293 & 173 & 215 & 115 & 395 & 50 \\
55 & 628 & 470 & 605 & 463 & 555 & 426 & 417 & 279 & 297 & 185 & 374 & 214 & 404 & 59 \\
56 & 592 & 439 & 532 & 411 & 540 & 409 & 532 & 369 & 325 & 207 & 267 & 160 & 352 & 106 \\
57 & 584 & 444 & 497 & 393 & 570 & 438 & 562 & 431 & 380 & 245 & 282 & 161 & 347 & 203 \\
58 & 524 & 390 & 528 & 402 & 474 & 375 & 487 & 365 & 442 & 334 & 280 & 167 & 254 & 142 \\
59 & 484 & 375 & 500 & 392 & 480 & 378 & 507 & 391 & 490 & 374 & 320 & 216 & 250 & 151 \\
60 & 486 & 372 & 415 & 310 & 453 & 334 & 448 & 337 & 425 & 319 & 380 & 267 & 273 & 166 \\
61 & 350 & 269 & 374 & 299 & 422 & 331 & 411 & 311 & 418 & 321 & 423 & 329 & 277 & 187 \\
Total & 6,745 & 5,093 & 5,443 & 4,216 & 4,415 & 3,388 & 5,063 & 3,481 & 3,973 & 2,658 & 2,867 & 1,793 & 4,095 & 1,168 \\
\hline
\end{tabular}

Table 4: Descriptive Statistics for Sample Age 51-61

\begin{tabular}{|c|c|c|c|c|c|c|c|c|c|c|c|c|}
\hline & \multicolumn{2}{|c|}{ 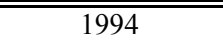 } & \multicolumn{2}{|c|}{1996} & \multicolumn{2}{|c|}{1998} & \multicolumn{2}{|c|}{2000} & \multicolumn{2}{|c|}{2002} & \multicolumn{2}{|c|}{2004} \\
\hline & All & SS.Er & All & SS.Er & All & SS.Er & All & SS.Er & All & SS.Er & All & SS.Er \\
\hline \multicolumn{13}{|l|}{ demographics (Mean) } \\
\hline age & 55.9 & 55.9 & 56.7 & 56.8 & 56.0 & 56.3 & 56.5 & 56.9 & 57.1 & 57.5 & 55.1 & 57.6 \\
\hline widow & 0.05 & 0.06 & 0.05 & 0.06 & 0.05 & 0.05 & 0.05 & 0.06 & 0.05 & 0.05 & 0.04 & 0.06 \\
\hline sep(or)div & 0.13 & 0.13 & 0.13 & 0.13 & 0.14 & 0.14 & 0.13 & 0.13 & 0.13 & 0.13 & 0.15 & 0.11 \\
\hline never married & 0.03 & 0.03 & 0.02 & 0.02 & 0.03 & 0.03 & 0.03 & 0.03 & 0.03 & 0.03 & 0.04 & 0.02 \\
\hline black & 0.15 & 0.14 & 0.15 & 0.13 & 0.14 & 0.13 & 0.13 & 0.12 & 0.14 & 0.12 & 0.14 & 0.11 \\
\hline other race & 0.03 & 0.03 & 0.03 & 0.03 & 0.04 & 0.03 & 0.04 & 0.03 & 0.04 & 0.03 & 0.08 & 0.03 \\
\hline schoo & 12.6 & 12.6 & 12.7 & 12.7 & 13.0 & 13.0 & 13.1 & 13.1 & 13.3 & 13.4 & 13.5 & 13.4 \\
\hline health & 0.30 & 0.30 & 0.30 & 0.30 & 0.32 & 0.33 & 0.29 & 0.29 & 0.32 & 0.32 & 0.31 & 0.33 \\
\hline health fair/poor & 0.13 & 0.12 & 0.12 & 0.11 & 0.15 & 0.15 & 0.13 & 0.12 & 0.12 & 0.12 & 0.16 & 0.14 \\
\hline \multicolumn{13}{|c|}{ Job Characteristics (Mean) } \\
\hline self-employed & 0.18 & 0.17 & 0.18 & 0.18 & 0.18 & 0.17 & 0.17 & 0.15 & 0.17 & 0.16 & 0.17 & 0.17 \\
\hline tenure (yrs) & 13.6 & 13.5 & 13.3 & 13.2 & 13.5 & 13.3 & 13.5 & 13.5 & 13.2 & 13.3 & 12.7 & 12.9 \\
\hline $\begin{array}{l}\text { pressured to retire }<65 \\
\text { by co-workers }\end{array}$ & 0.00 & 0.00 & 0.12 & 0.12 & 0.12 & 0.11 & 0.11 & 0.10 & 0.11 & 0.11 & 0.11 & 0.11 \\
\hline $\begin{array}{l}\text { transition low } \\
\text { demanding job easy }\end{array}$ & 0.00 & 0.00 & 0.25 & 0.26 & 0.26 & 0.27 & 0.29 & 0.30 & 0.30 & 0.30 & 0.30 & 0.29 \\
\hline \multicolumn{13}{|c|}{ Median wealth and earnings (USD 2004) } \\
\hline total fi & 144,621 & 141,863 & 145,532 & 144,943 & 141,131 & 140,550 & 153,932 & 154,482 & 159,973 & 154,710 & 161,000 & 170,500 \\
\hline liquid fin. wealth & 19,169 & 19,164 & 18,704 & 18,885 & 18,585 & 17,424 & 24,739 & 26,388 & 28,416 & 26,311 & 14,000 & 22,000 \\
\hline Total HH Income & 58,257 & 58,768 & 62,267 & 61,785 & 63,886 & 63,422 & 66,230 & 65,784 & 66,856 & 65,252 & 68,024 & 64,760 \\
\hline Current AIME & & 2,018 & & 2,045 & & 2,273 & & 2,367 & & 2,370 & & 2,304 \\
\hline$\%$ with pension plan & 0.567 & 0.575 & 0.569 & 0.575 & 0.587 & 0.594 & 0.611 & 0.620 & 0.590 & 0.592 & 0.590 & 0.588 \\
\hline & 0.270 & 0.281 & 0.305 & 0.314 & 0.361 & 0.366 & 0.360 & 0.369 & 0.359 & 0.366 & 0.411 & 0.388 \\
\hline$\%$ with DB Plan & 0.370 & 0.373 & 0.343 & 0.344 & 0.338 & 0.343 & 0.330 & 0.336 & 0.314 & 0.311 & 0.296 & 0.312 \\
\hline
\end{tabular}

Notes: Variable definitions in Appendix . All statistics are unweighted. Dollar amounts converted to \$2004 using the BLS consumer price index. 
Table 5: Summary Statistics of Expectations for Workers Age 51-61 Males

\begin{tabular}{lrrrrrr}
\hline \hline mean and \% $>0$ & \multicolumn{6}{c}{ probability work at 65 by year } \\
age & 1992 & 1994 & 1996 & 1998 & 2000 & 2002 \\
\hline $51-54$ & 27.26 & 26.88 & 24.81 & 30.16 & 31.24 & 29.43 \\
& 0.52 & 0.59 & 0.55 & 0.64 & 0.69 & 0.71 \\
$55-57$ & 31.96 & 26.13 & 27.63 & 29.62 & 32.36 & 28.94 \\
& 0.56 & 0.56 & 0.55 & 0.60 & 0.68 & 0.68 \\
$58-61$ & 30.01 & 29.13 & 30.77 & 29.04 & 32.11 & 32.51 \\
& 0.54 & 0.55 & 0.57 & 0.56 & 0.61 & 0.66 \\
\hline Total & 29.32 & 27.45 & 28.79 & 29.50 & 31.98 & 31.20 \\
& 0.53 & 0.57 & 0.56 & 0.59 & 0.64 & 0.67 \\
\hline mean and \%>666 & Age Expect to Claim Social Security & Benefits by year \\
age & 1992 & 1994 & 1996 & 1998 & 2000 & 2002 \\
\hline $51-54$ & 63.46 & 63.45 & 63.64 & 63.83 & 64.41 & 64.26 \\
& 0.04 & 0.04 & 0.06 & 0.07 & 0.12 & 0.09 \\
$55-57$ & 63.42 & 63.38 & 63.55 & 63.86 & 63.82 & 64.14 \\
& 0.04 & 0.04 & 0.05 & 0.08 & 0.08 & 0.11 \\
$58-61$ & 63.65 & 63.46 & 63.72 & 63.64 & 63.70 & 64.00 \\
& 0.05 & 0.05 & 0.07 & 0.08 & 0.08 & 0.11 \\
\hline Total & 63.50 & 63.43 & 63.64 & 63.76 & 63.87 & 64.07 \\
& 0.04 & 0.04 & 0.06 & 0.08 & 0.09 & 0.11 \\
\hline \hline Notes: & & &
\end{tabular}

Notes: mean (including zeros) and $\%$ larger than 0 for each year and age group. Workers aged 51-61.

\section{Females}

\begin{tabular}{lrrrrrr}
\hline \hline mean and \%>0 & \multicolumn{6}{c}{ probability work at 65 by year } \\
age & 1992 & 1994 & 1996 & 1998 & 2000 & 2002 \\
\hline $51-54$ & 22.14 & 19.78 & 20.80 & 23.21 & 24.86 & 22.91 \\
& 0.46 & 0.49 & 0.47 & 0.54 & 0.57 & 0.59 \\
$55-57$ & 20.51 & 20.91 & 25.78 & 22.82 & 25.69 & 27.35 \\
& 0.42 & 0.47 & 0.52 & 0.51 & 0.55 & 0.62 \\
$58-61$ & 22.65 & 20.92 & 23.35 & 23.88 & 28.75 & 28.02 \\
& 0.43 & 0.44 & 0.45 & 0.50 & 0.59 & 0.58 \\
\hline Total & 21.85 & 20.45 & 23.41 & 23.33 & 26.78 & 26.77 \\
& 0.443 & 0.469 & 0.477 & 0.516 & 0.573 & 0.596 \\
\hline mean and \%>66 & Age Expect to Claim Social Security & Benefits by year \\
age & 1992 & 1994 & 1996 & 1998 & 2000 & 2002 \\
\hline $51-54$ & 63.41 & 63.44 & 63.69 & 63.83 & 64.09 & 64.18 \\
& 0.04 & 0.04 & 0.06 & 0.07 & 0.09 & 0.15 \\
$55-57$ & 63.45 & 63.35 & 63.74 & 63.71 & 63.65 & 64.34 \\
& 0.03 & 0.05 & 0.07 & 0.08 & 0.07 & 0.14 \\
$58-61$ & 63.61 & 63.56 & 63.69 & 63.72 & 63.94 & 63.69 \\
& 0.06 & 0.06 & 0.07 & 0.08 & 0.08 & 0.07 \\
\hline Total & 63.47 & 63.45 & 63.71 & 63.75 & 63.91 & 64.00 \\
& 0.04 & 0.05 & 0.07 & 0.08 & 0.08 & 0.11 \\
\hline \hline Notes & mat & & &
\end{tabular}

Notes: mean (including zeros) and \% larger than 0 for each year and age group. Workers aged 51-61. 
Table 6: Survival Probabilities based on Life-Tables and Subjective Probabilities Conditional on Surviving to Age 55

\begin{tabular}{|c|c|c|c|c|c|}
\hline \multirow[b]{2}{*}{ age } & \multicolumn{2}{|c|}{ conditional survival } & \multirow[b]{2}{*}{ Std. } & \multirow[b]{2}{*}{ Min } & \multirow[b]{2}{*}{ Max } \\
\hline & life-table & subjective & & & \\
\hline \multicolumn{6}{|l|}{ Males } \\
\hline 55 & 1 & 1 & 0 & 1 & 1 \\
\hline 56 & 0.991 & 0.987 & 0.005 & 0.978 & 0.991 \\
\hline 57 & 0.980 & 0.974 & 0.009 & 0.954 & 0.981 \\
\hline 58 & 0.969 & 0.960 & 0.014 & 0.930 & 0.971 \\
\hline 59 & 0.957 & 0.945 & 0.019 & 0.904 & 0.960 \\
\hline 60 & 0.944 & 0.929 & 0.024 & 0.878 & 0.948 \\
\hline 65 & 0.862 & 0.838 & 0.052 & 0.729 & 0.879 \\
\hline 75 & 0.610 & 0.590 & 0.102 & 0.381 & 0.675 \\
\hline 85 & 0.271 & 0.299 & 0.102 & 0.101 & 0.393 \\
\hline 95 & 0.037 & 0.082 & 0.044 & 0.007 & 0.130 \\
\hline 105 & 0.001 & 0.007 & 0.005 & 0.000 & 0.014 \\
\hline 109 & 0.000 & 0.001 & 0.001 & 0.000 & 0.003 \\
\hline \multicolumn{6}{|c|}{ Females } \\
\hline 55 & 1 & 1 & 0 & 1 & 1 \\
\hline 56 & 0.995 & 0.990 & 0.003 & 0.982 & 0.993 \\
\hline 57 & 0.989 & 0.979 & 0.007 & 0.964 & 0.985 \\
\hline 58 & 0.982 & 0.967 & 0.011 & 0.944 & 0.977 \\
\hline 59 & 0.975 & 0.955 & 0.015 & 0.923 & 0.968 \\
\hline 60 & 0.967 & 0.942 & 0.019 & 0.901 & 0.958 \\
\hline 65 & 0.918 & 0.863 & 0.042 & 0.774 & 0.900 \\
\hline 75 & 0.751 & 0.633 & 0.091 & 0.444 & 0.717 \\
\hline 85 & 0.457 & 0.334 & 0.102 & 0.134 & 0.438 \\
\hline 95 & 0.111 & 0.092 & 0.048 & 0.010 & 0.151 \\
\hline 105 & 0.003 & 0.007 & 0.005 & 0.000 & 0.015 \\
\hline 109 & 0.000 & 0.001 & 0.001 & 0.000 & 0.003 \\
\hline
\end{tabular}


Table 7a: Expected Social Security Wealth and Incentives to Claim Social Security Benefits for those aged 51-61 from 1992 to 2004: Males

\begin{tabular}{|c|c|c|c|c|c|c|c|c|c|}
\hline \multicolumn{10}{|c|}{ using life-table mortality rates } \\
\hline \multirow[b]{2}{*}{ quantile } & \multirow{2}{*}{$\begin{array}{c}\text { SS } \\
\text { wealth } 62\end{array}$} & \multirow{2}{*}{$\begin{array}{c}\text { relative to } \\
\text { median }\end{array}$} & \multicolumn{7}{|c|}{ accrual (\% of W62) } \\
\hline & & & 62 & 63 & 64 & 65 & 66 & 67 & 68 \\
\hline 10th & 90,157 & 0.503 & 0.42 & -0.39 & -1.13 & -2.55 & -3.09 & -3.58 & -4.07 \\
\hline 25th & 135,609 & 0.757 & 0.72 & -0.09 & -0.83 & -1.71 & -2.34 & -2.91 & -3.48 \\
\hline Median & 179,091 & 1.000 & 1.32 & 0.48 & -0.30 & -1.03 & -1.65 & -2.27 & -2.88 \\
\hline 75th & 213,326 & 1.191 & 1.81 & 0.91 & 0.10 & -0.46 & -0.77 & -1.52 & -2.21 \\
\hline 90th & 233,987 & 1.307 & 2.59 & 1.64 & 0.80 & 0.11 & 0.06 & -0.72 & -1.46 \\
\hline \multicolumn{10}{|c|}{ using subjective mortality rates } \\
\hline & SS & relative to & \multicolumn{7}{|c|}{ accrual $(\%$ of W62) } \\
\hline quantile & wealth 62 & median & 62 & 63 & 64 & 65 & 66 & 67 & 68 \\
\hline 10th & 87,043 & 0.485 & -0.04 & -0.99 & -1.86 & -3.01 & -3.45 & -4.04 & -4.64 \\
\hline 25th & 129,972 & 0.724 & 0.81 & 0.01 & -0.70 & -1.76 & -2.27 & -2.78 & -3.28 \\
\hline Median & 179,536 & 1.000 & 1.47 & 0.65 & -0.09 & -0.79 & -1.33 & -1.90 & -2.45 \\
\hline 75th & 219,491 & 1.223 & 2.09 & 1.27 & 0.54 & -0.10 & -0.40 & -1.06 & -1.65 \\
\hline 90th & 245,663 & 1.368 & 2.85 & 1.95 & 1.16 & 0.57 & 0.39 & -0.31 & -0.97 \\
\hline
\end{tabular}

Notes: median social security wealth at 62 for the sample aged 51-61 between 1992 and 2004. Expressed in \$2004 USD. The accrual at age a is defined in terms of the \% difference between the expected present value of social security wealth if claimed at $a+1$ compared to age $a$.

Table 7b: Expected Social Security Wealth and Incentives to Claim Social Secutity Benefits for those aged 51-61 from 1992 to 2004: Females

\begin{tabular}{|c|c|c|c|c|c|c|c|c|c|}
\hline \multicolumn{10}{|c|}{ using life-table mortality rates } \\
\hline \multirow[b]{2}{*}{ quantile } & \multirow{2}{*}{$\begin{array}{c}\text { SS } \\
\text { wealth } 62\end{array}$} & \multirow{2}{*}{$\begin{array}{c}\text { relative to } \\
\text { median }\end{array}$} & \multicolumn{7}{|c|}{ accrual $(\%$ of W62) } \\
\hline & & & 62 & 63 & 64 & 65 & 66 & 67 & 68 \\
\hline 10th & 37,432 & 0.209 & 1.65 & 0.87 & 0.18 & -0.34 & -0.96 & -1.54 & -2.05 \\
\hline 25 th & 85,422 & 0.477 & 2.52 & 1.67 & 0.93 & 0.21 & -0.16 & -0.75 & -1.31 \\
\hline Median & 119,872 & 0.669 & 3.55 & 2.67 & 1.88 & 1.09 & 0.83 & 0.17 & -0.46 \\
\hline 75th & 162,557 & 0.908 & 4.53 & 3.66 & 2.88 & 2.15 & 1.83 & 1.12 & 0.45 \\
\hline 90th & 213,007 & 1.189 & 5.82 & 4.91 & 4.07 & 3.35 & 3.22 & 2.47 & 1.84 \\
\hline \multicolumn{10}{|c|}{ using subjective mortality rates } \\
\hline & SS & relative to & \multicolumn{7}{|c|}{ accrual $(\%$ of W62) } \\
\hline quantile & wealth 62 & median & 62 & 63 & 64 & 65 & 66 & 67 & 68 \\
\hline 10th & 33,575 & 0.187 & 0.89 & 0.02 & -0.74 & -1.77 & -2.25 & -2.83 & -3.45 \\
\hline 25 th & 74,172 & 0.413 & 1.73 & 0.88 & 0.13 & -0.59 & -1.06 & -1.68 & -2.26 \\
\hline Median & 108,499 & 0.604 & 2.84 & 1.95 & 1.15 & 0.42 & 0.16 & -0.51 & -1.14 \\
\hline 75 th & 150,337 & 0.837 & 4.00 & 3.12 & 2.33 & 1.57 & 1.31 & 0.58 & -0.08 \\
\hline 90th & 201,923 & 1.125 & 5.28 & 4.36 & 3.56 & 2.88 & 2.69 & 1.97 & 1.33 \\
\hline
\end{tabular}

Notes: median social security wealth at 62 for the sample aged 51-61 between 1992 and 2004. Expressed in \$2004 USD. The accrual at age a is defined in terms of the $\%$ difference between the expected present value of social security wealth if claimed at $a+1$ compared to age $a$. 
Table 8a: Projected Loss from the Earnings Test before 2000: Males

\begin{tabular}{|c|c|c|c|c|c|c|}
\hline \multirow[b]{4}{*}{ quantile } & \multicolumn{6}{|c|}{ Predicted Loss due to the earnings test } \\
\hline & \multicolumn{3}{|c|}{ age 62} & \multicolumn{3}{|c|}{ normal retirement age } \\
\hline & \multirow[b]{2}{*}{ myopic } & \multicolumn{2}{|c|}{ forward-looking using } & \multirow[b]{2}{*}{ myopic } & \multicolumn{2}{|c|}{ forward-looking using } \\
\hline & & life-table & subjective & & life-table & subjective \\
\hline \multicolumn{7}{|c|}{ Loss in dollars } \\
\hline 10th & 0 & 0 & 0 & 0 & 0 & 0 \\
\hline 25 th & 3,003 & 868 & 832 & 0 & 0 & 0 \\
\hline 50th & 12,020 & 3,485 & 3,010 & 6,913 & 1,549 & 1,114 \\
\hline 75th & 15,300 & 4,387 & 3,698 & 15,486 & 3,473 & 2,785 \\
\hline 90th & 16,856 & 4,758 & 4,336 & 21,201 & 5,451 & 4,727 \\
\hline \multicolumn{7}{|c|}{ as fraction of earnings (positive earnings) } \\
\hline 10th & 0 & 0 & 0 & 0 & 0 & 0 \\
\hline 25 th & 0.193 & 0.055 & 0.043 & 0.091 & 0.016 & 0.005 \\
\hline 50th & 0.239 & 0.069 & 0.059 & 0.191 & 0.039 & 0.030 \\
\hline 75th & 0.292 & 0.084 & 0.080 & 0.233 & 0.062 & 0.055 \\
\hline 90th & 0.327 & 0.095 & 0.098 & 0.251 & 0.077 & 0.075 \\
\hline \multicolumn{7}{|c|}{ as fraction of current liquid assets (positive assets) } \\
\hline 10th & -0.571 & -0.162 & -0.159 & -0.289 & -0.064 & -0.052 \\
\hline 25 th & 0 & 0 & 0 & 0 & 0 & 0 \\
\hline 50th & 0.087 & 0.025 & 0.021 & 0.057 & 0.013 & 0.008 \\
\hline 75th & 0.439 & 0.127 & 0.115 & 0.310 & 0.075 & 0.059 \\
\hline 90th & 2.128 & 0.603 & 0.555 & 1.404 & 0.347 & 0.292 \\
\hline
\end{tabular}

Notes: workers aged 51-61 interviewed before 2000 .

Table 8b: Projected Loss from the Earnings Test before 2000: Females

\begin{tabular}{|c|c|c|c|c|c|c|}
\hline \multirow[b]{4}{*}{ quantile } & \multicolumn{6}{|c|}{ Predicted Loss due to the earnings test } \\
\hline & \multicolumn{3}{|c|}{ age 62} & \multicolumn{3}{|c|}{ normal retirement age } \\
\hline & \multirow[b]{2}{*}{ myopic } & \multicolumn{2}{|c|}{ forward-looking using } & \multirow[b]{2}{*}{ myopic } & \multicolumn{2}{|c|}{ forward-looking using } \\
\hline & & life-table & subjective & & life-table & subjective \\
\hline \multicolumn{7}{|c|}{ Loss in dollars } \\
\hline 10th & 0 & 0 & 0 & 0 & -174 & 0 \\
\hline 25 th & 0 & 0 & 0 & 0 & 0 & 0 \\
\hline 50 th & 4,852 & 727 & 1,095 & 575 & 0 & 0 \\
\hline 75 th & 9,463 & 1,413 & 2,067 & 5,811 & 448 & 750 \\
\hline 90th & 12,882 & 1,895 & 2,720 & 11,730 & 1,311 & 1,940 \\
\hline \multicolumn{7}{|c|}{ as fraction of earnings (positive earnings) } \\
\hline 10th & 0.000 & 0.000 & 0.000 & 0 & -0.007 & -0.001 \\
\hline 25th & 0.077 & 0.009 & 0.018 & 0 & 0 & 0 \\
\hline 50th & 0.216 & 0.031 & 0.041 & 0.076 & 0 & 0.002 \\
\hline 75th & 0.264 & 0.039 & 0.060 & 0.170 & 0.017 & 0.026 \\
\hline 90th & 0.294 & 0.045 & 0.077 & 0.217 & 0.035 & 0.049 \\
\hline \multicolumn{7}{|c|}{ as fraction of current liquid assets (positive assets) } \\
\hline 10th & -0.318 & -0.047 & -0.076 & -0.01061 & -0.01384 & -0.0127036 \\
\hline 25 th & 0.000 & 0.000 & 0.000 & 0 & 0 & 0 \\
\hline 50th & 0.022 & 0.003 & 0.005 & 0 & 0 & 0 \\
\hline 75th & 0.240 & 0.035 & 0.052 & 0.100528 & 0.007395 & 0.0118125 \\
\hline 90th & 1.338 & 0.195 & 0.320 & 0.612906 & 0.062906 & 0.0946192 \\
\hline
\end{tabular}

Notes: workers aged 51-61 interviewed before 2000. 
Table 9: Earnings Test Incentives by Birth Cohort

\begin{tabular}{|c|c|c|c|c|c|c|c|c|}
\hline \multirow{2}{*}{\multicolumn{3}{|c|}{ mean $\%$ of earnings at }} & \multicolumn{3}{|c|}{ Age 62} & \multicolumn{3}{|c|}{ Normal Retirement Age } \\
\hline & & & \multirow[b]{2}{*}{ moypic } & \multicolumn{2}{|c|}{ forward-looking } & \multirow[b]{2}{*}{ myopic } & \multicolumn{2}{|c|}{ forward-looking } \\
\hline birth year & NRA & DRC & & life-table & subjective & & life-table & subjective \\
\hline 1932 & 65 & 0.050 & 0.188 & 0.047 & 0.052 & 0.130 & 0.056 & 0.056 \\
\hline 1933 & 65 & 0.055 & 0.191 & 0.045 & 0.055 & 0.115 & 0.040 & 0.042 \\
\hline 1934 & 65 & 0.055 & 0.200 & 0.049 & 0.057 & 0.128 & 0.043 & 0.045 \\
\hline 1935 & 65 & 0.060 & 0.206 & 0.050 & 0.057 & 0.133 & 0.038 & 0.039 \\
\hline 1936 & 65 & 0.060 & 0.203 & 0.047 & 0.055 & 0.131 & 0.037 & 0.039 \\
\hline 1937 & 65 & 0.065 & 0.205 & 0.045 & 0.053 & 0.127 & 0.028 & 0.029 \\
\hline 1938 & 65.02 & 0.065 & 0.199 & 0.044 & 0.050 & 0.127 & 0.028 & 0.028 \\
\hline 1939 & 65.04 & 0.070 & 0.208 & 0.047 & 0.052 & 0.125 & 0.019 & 0.019 \\
\hline 1940 & 65.06 & 0.070 & 0.206 & 0.046 & 0.048 & 0.124 & 0.018 & 0.017 \\
\hline 1941 & 65.08 & 0.075 & 0.203 & 0.043 & 0.046 & 0.129 & 0.011 & 0.008 \\
\hline 1942 & 66 & 0.075 & 0.185 & 0.031 & 0.038 & 0.092 & 0.005 & 0.006 \\
\hline 1943 & 66 & 0.080 & 0.179 & 0.041 & 0.047 & 0.087 & 0.001 & 0.002 \\
\hline 1944 & 66 & 0.080 & 0.191 & 0.043 & 0.051 & 0.099 & 0.001 & 0.003 \\
\hline 1945 & 66 & 0.080 & 0.196 & 0.045 & 0.051 & 0.098 & 0.002 & 0.003 \\
\hline 1946 & 66 & 0.080 & 0.194 & 0.046 & 0.050 & 0.110 & 0.003 & 0.002 \\
\hline 1947 & 66 & 0.080 & 0.198 & 0.047 & 0.055 & 0.108 & 0.005 & 0.005 \\
\hline
\end{tabular}

Notes: Sample of workers aged 51-61 between 1992 and 1998.

Table 10: Unconditional Difference-in-Difference Grouping Estimates

\begin{tabular}{|c|c|c|c|c|c|c|}
\hline \multirow{3}{*}{$\begin{array}{l}\text { Myopic loss } \\
\text { \% of benefit at NRA } \\
\text { Group }\end{array}$} & \multicolumn{3}{|c|}{ Males } & \multicolumn{3}{|c|}{ Females } \\
\hline & \multicolumn{3}{|c|}{ Males: mean P65 $(\mathrm{N}=875)$} & \multicolumn{3}{|c|}{ mean P65 $(\mathrm{N}=632)$} \\
\hline & 1998 & 2002 & Diff 2002-1998 & 1998 & 2002 & Diff 2002-1998 \\
\hline$\overline{0}$ & 36.30 & 36.08 & -0.22 & 25.57 & 27.49 & 1.92 \\
\hline 1 to $49 \%$ & 34.48 & 37.24 & 2.76 & 24.88 & 27.34 & 2.46 \\
\hline 50 to $99 \%$ & 26.26 & 27.40 & 1.14 & 25.06 & 29.13 & 4.07 \\
\hline $100 \%$ & 31.32 & 31.58 & 0.26 & 35.59 & 42.35 & 6.76 \\
\hline Group & \multicolumn{3}{|c|}{$\% \mathrm{P} 65>0(\mathrm{~N}=875)$} & \multicolumn{3}{|c|}{$\% \mathrm{P} 65>0(\mathrm{~N}=632)$} \\
\hline$\overline{0}$ & 65.91 & 65.15 & -0.76 & 53.36 & 55.37 & 2.01 \\
\hline 1 to $49 \%$ & 65.50 & 72.49 & 6.99 & 57.91 & 61.39 & 3.49 \\
\hline 50 to $99 \%$ & 67.46 & 68.25 & 0.79 & 56.15 & 65.24 & 9.09 \\
\hline $100 \%$ & 73.68 & 73.68 & 0.00 & 64.71 & 70.59 & 5.88 \\
\hline Group & \multicolumn{3}{|c|}{$\% \mathrm{EC}>\mathrm{NRA}(\mathrm{N}=829)$} & \multicolumn{3}{|c|}{$\% \mathrm{EC}>\mathrm{NRA}(\mathrm{N}=671)$} \\
\hline$\overline{0}$ & 8.20 & 13.11 & 4.92 & 6.59 & 9.52 & 2.93 \\
\hline 1 to $49 \%$ & 7.02 & 7.46 & 0.44 & 6.61 & 7.76 & 1.15 \\
\hline 50 to $99 \%$ & 7.93 & 9.66 & 1.72 & 11.70 & 13.83 & 2.13 \\
\hline $100 \%$ & 12.90 & 16.13 & 3.23 & 25.00 & 15.00 & -10.00 \\
\hline
\end{tabular}

Notes: Sample of workers 51-61 who report in both waves. 
Table 11a: Conditional Difference-in-Difference Grouping Estimates for Males

\begin{tabular}{|c|c|c|c|c|c|}
\hline \multirow{3}{*}{$\begin{array}{l}\text { Males } \\
\text { repeal }(\mathrm{REP}=1) \\
\text { Control is no tax }\end{array}$} & tobit P65 & RE tobit P65 & $\begin{array}{c}\text { RE probit } \\
(\mathrm{P} 65>0)\end{array}$ & $\begin{array}{c}\text { Ordered Probit } \\
(\text { EC: <NRA, } \\
\text { NRA, >NRA) })\end{array}$ & $\begin{array}{c}\text { RE probit } \\
(\mathrm{EC}>\mathrm{NRA})\end{array}$ \\
\hline & 1.963 & 1.253 & 0.114 & -0.161 & 0.383 \\
\hline & $(0.640)$ & $(0.632)$ & $(0.437)$ & $(0.098)$ & $(0.049)$ \\
\hline \multicolumn{6}{|l|}{ Groups X REP } \\
\hline \multirow[t]{2}{*}{$1-50 \%$ of $\mathrm{P}$} & 9.927 & 5.944 & 0.448 & 0.047 & -0.090 \\
\hline & $(0.053)$ & $(0.058)$ & $(0.010)$ & $(0.688)$ & $(0.698)$ \\
\hline \multirow[t]{2}{*}{$51-99 \%$ of $\mathrm{P}$} & 10.388 & 7.505 & 0.229 & 0.113 & 0.217 \\
\hline & $(0.040)$ & $(0.015)$ & $(0.169)$ & $(0.329)$ & $(0.342)$ \\
\hline \multirow[t]{2}{*}{$100 \%$ if $\mathrm{P}$} & -4.431 & 3.033 & 0.018 & -0.059 & -0.375 \\
\hline & $(0.638)$ & $(0.601)$ & $(0.954)$ & $(0.768)$ & $(0.314)$ \\
\hline $\mathrm{N}$ & 4146 & 4146 & 4146 & 3791 & 3791 \\
\hline
\end{tabular}

Table 11b: Conditional Difference-in-Difference Grouping Estimates for Females

\begin{tabular}{|c|c|c|c|c|c|}
\hline Females & tobit P65 & RE tobit P65 & $\begin{array}{l}\text { RE probit } \\
(\mathrm{P} 65>0)\end{array}$ & $\begin{array}{c}\text { Ordered Probit } \\
(\mathrm{EC}:<\mathrm{NRA}, \\
\text { NRA, >NRA) }\end{array}$ & $\begin{array}{c}\text { RE probit } \\
(\mathrm{EC}>\mathrm{NRA})\end{array}$ \\
\hline repeal $(\mathrm{REP}=1)$ & 8.225 & 4.630 & 0.326 & -0.291 & 0.195 \\
\hline Control is no tax & $(0.007)$ & $(0.026)$ & $(0.000)$ & $(0.000)$ & $(0.171)$ \\
\hline \multicolumn{6}{|l|}{ Groups X REP } \\
\hline $1-50 \%$ of $\mathrm{P}$ & $\begin{array}{c}1.810 \\
(0.644)\end{array}$ & $\begin{array}{c}2.394 \\
(0.360)\end{array}$ & $\begin{array}{c}0.127 \\
(0.264)\end{array}$ & $\begin{array}{c}0.126 \\
(0.167)\end{array}$ & $\begin{array}{c}0.101 \\
(0.571)\end{array}$ \\
\hline $51-99 \%$ of $\mathrm{P}$ & $\begin{array}{c}0.458 \\
(0.925)\end{array}$ & $\begin{array}{c}1.956 \\
(0.550)\end{array}$ & $\begin{array}{c}0.066 \\
(0.647)\end{array}$ & $\begin{array}{c}0.074 \\
(0.496)\end{array}$ & $\begin{array}{l}-0.171 \\
(0.388)\end{array}$ \\
\hline $100 \%$ if $\mathrm{P}$ & $\begin{array}{l}-6.206 \\
(0.617)\end{array}$ & $\begin{array}{l}-2.709 \\
(0.736)\end{array}$ & $\begin{array}{l}-0.365 \\
(0.339)\end{array}$ & $\begin{array}{l}-0.225 \\
(0.396)\end{array}$ & $\begin{array}{l}-0.164 \\
(0.702)\end{array}$ \\
\hline $\mathrm{N}$ & 5306 & 5306 & 5306 & 4363 & 4363 \\
\hline
\end{tabular}

Notes: Sample of workers aged 51-61 from 1996 to 2002. Pvalue under parameter estimates. P65 is the subjective probability to work full-time past 65 . EC represents the age at which the respondent expects to claim Social Security Benefits. REP is a dummy variable that takes value 1 for 2000 and 2002 observations. The grouping is done by the share of benefits loss at NRA. Controls for age dummies, demographics, job characteristics, current financial resources and projected social security wealth and accrual at age 62 as well as AIME. Full results in Appendix. 
Table 12 Actual Claiming Decisions and Differences between Actual and Expected Claiming Age

\begin{tabular}{|c|c|c|c|c|c|c|}
\hline \multirow{3}{*}{$\begin{array}{l}\text { mean deviation } \\
\mathrm{N}\end{array}$} & \multicolumn{2}{|c|}{ Deviation } & \multirow{3}{*}{$\begin{array}{c}\text { Diff } \\
2000-1998\end{array}$} & \multicolumn{2}{|c|}{ claim at NRA } & \multirow{3}{*}{$\begin{array}{c}\text { Diff } \\
2000-1998\end{array}$} \\
\hline & \multicolumn{2}{|c|}{ turning 65 in } & & \multicolumn{2}{|c|}{ turning 65 in } & \\
\hline & 1998 & 2000 & & 1998 & 2000 & \\
\hline \multicolumn{7}{|l|}{ gender } \\
\hline \multirow[t]{2}{*}{ female } & 0.086 & -0.451 & -0.537 & 0.800 & 0.837 & 0.037 \\
\hline & 70 & 73 & & 70 & 73 & \\
\hline \multirow[t]{2}{*}{ male } & 0.430 & -0.433 & -0.863 & 0.701 & 0.832 & 0.131 \\
\hline & 93 & 90 & & 93 & 90 & \\
\hline \multirow{2}{*}{$\begin{array}{l}\text { fraction benefit loss } \\
\text { at NRA }\end{array}$} & & & Diff 2000- & & & Diff 2000- \\
\hline & 1998 & 2000 & 1998 & 1998 & 2000 & 1998 \\
\hline \multirow[t]{2}{*}{0} & -0.200 & -0.154 & 0.046 & 0.862 & 0.862 & 0.000 \\
\hline & 35 & 39 & & 35 & 39 & \\
\hline \multirow[t]{2}{*}{$1-50 \%$} & -0.222 & -0.225 & -0.003 & 0.781 & 0.880 & 0.099 \\
\hline & 45 & 40 & & 45 & 40 & \\
\hline \multirow[t]{2}{*}{$51-99 \%$} & 0.487 & 0.029 & -0.458 & 0.712 & 0.795 & 0.084 \\
\hline & 39 & 35 & & 39 & 35 & \\
\hline \multirow[t]{2}{*}{$100 \%$} & -0.222 & -0.779 & -0.557 & 0.571 & 0.840 & 0.269 \\
\hline & 18 & 18 & & 18 & 18 & \\
\hline
\end{tabular}

Notes: sample of respondents who turn 65 in given wave, have not claimed before 65 and will not claim after age 69 (for deviations). The variable in the deviation is the difference between the age at which benefits were claimed and the age at which the respondent expected to claim as of previous wave. For the second panel, the fraction of respondents turning 65 and claiming is presented. 
Appendix: Complete Results (in order Males and Females)

\begin{tabular}{|c|c|c|c|c|c|}
\hline covariate & tobit P65 & RE tobit P65 & $\begin{array}{c}\text { RE probit } \\
(\mathrm{P} 65>0)\end{array}$ & $\begin{array}{c}\text { Ordered Probit } \\
(\text { EC: }<\text { NRA, } \\
\text { NRA, }>\text { NRA)) }\end{array}$ & $\begin{array}{c}\text { RE probit } \\
(\mathrm{EC}>\mathrm{NRA})\end{array}$ \\
\hline widow & -7.776 & -7.046 & -0.373 & 0.039 & 0.515 \\
\hline (ref: married) & 0.283 & 0.173 & 0.190 & 0.807 & 0.099 \\
\hline \multirow[t]{2}{*}{ divorced } & -1.325 & 0.749 & 0.076 & -0.013 & 0.026 \\
\hline & 0.673 & 0.741 & 0.589 & 0.856 & 0.872 \\
\hline \multirow[t]{2}{*}{ never married } & 3.236 & 2.186 & 0.381 & 0.034 & 0.124 \\
\hline & 0.590 & 0.595 & 0.205 & 0.792 & 0.677 \\
\hline \multirow[t]{2}{*}{ black } & -13.204 & -10.960 & -0.646 & -0.313 & -0.338 \\
\hline & 0.000 & 0.000 & 0.000 & 0.000 & 0.093 \\
\hline \multirow[t]{2}{*}{ other race } & 6.348 & 3.513 & -0.156 & 0.147 & 0.257 \\
\hline & 0.216 & 0.377 & 0.538 & 0.202 & 0.327 \\
\hline \multirow[t]{2}{*}{ years schooling } & 2.018 & 1.187 & 0.069 & 0.046 & 0.125 \\
\hline & 0.000 & 0.000 & 0.000 & 0.000 & 0.000 \\
\hline \multirow[t]{2}{*}{ health good } & -8.429 & -5.450 & -0.189 & -0.090 & -0.096 \\
\hline & 0.000 & 0.000 & 0.016 & 0.052 & 0.354 \\
\hline \multirow[t]{2}{*}{ health fair/poor } & -4.853 & -0.579 & -0.004 & 0.064 & -0.040 \\
\hline & 0.240 & 0.844 & 0.984 & 0.550 & 0.859 \\
\hline \multirow{2}{*}{ self-employed } & 30.210 & 20.014 & 0.793 & 0.113 & 0.389 \\
\hline & 0.000 & 0.000 & 0.000 & 0.065 & 0.004 \\
\hline \multirow{2}{*}{ tenure current job } & -0.265 & -0.240 & -0.014 & -0.003 & -0.009 \\
\hline & 0.002 & 0.000 & 0.000 & 0.110 & 0.047 \\
\hline pressure to retire & -5.316 & -4.501 & -0.255 & -0.195 & -0.037 \\
\hline$<65$ from co-workers & 0.070 & 0.024 & 0.014 & 0.004 & 0.810 \\
\hline transition less & 5.463 & 2.041 & 0.105 & 0.035 & 0.183 \\
\hline demanding job poss. & 0.012 & 0.152 & 0.180 & 0.465 & 0.080 \\
\hline \multirow[t]{2}{*}{ 1st quntile wealth } & 17.377 & 13.610 & 0.394 & 0.266 & 0.366 \\
\hline & 0.000 & 0.000 & 0.004 & 0.000 & 0.024 \\
\hline 2nd quntile wealth & 6.348 & 5.738 & 0.083 & 0.058 & 0.082 \\
\hline (ref: 3rd quintile) & 0.025 & 0.002 & 0.437 & 0.360 & 0.556 \\
\hline \multirow[t]{2}{*}{ 4th quntile wealth } & -7.240 & -3.284 & -0.220 & -0.113 & -0.239 \\
\hline & 0.009 & 0.075 & 0.033 & 0.064 & 0.080 \\
\hline \multirow[t]{2}{*}{5 th quntile wealth } & -16.386 & -9.125 & -0.521 & -0.104 & -0.208 \\
\hline & 0.000 & 0.000 & 0.000 & 0.110 & 0.150 \\
\hline has DB plan current & -14.619 & -7.068 & -0.170 & -0.116 & -0.186 \\
\hline job & 0.000 & 0.000 & 0.056 & 0.021 & 0.100 \\
\hline has DC plan current & 1.391 & 0.978 & 0.072 & 0.127 & 0.195 \\
\hline job & 0.502 & 0.481 & 0.360 & 0.006 & 0.054 \\
\hline \multirow[t]{2}{*}{ total $\mathrm{HH}$ income } & $1.145 \mathrm{E}-05$ & $9.023 \mathrm{E}-06$ & 1.862E-06 & $2.998 \mathrm{E}-07$ & $1.663 \mathrm{E}-07$ \\
\hline & 0.015 & 0.003 & 0.000 & 0.008 & 0.412 \\
\hline Social Security wealth & $3.657 \mathrm{E}-04$ & $3.176 \mathrm{E}-04$ & $1.034 \mathrm{E}-05$ & $8.626 \mathrm{E}-06$ & 7.048E-06 \\
\hline age 62 - subjective & 0.000 & 0.000 & 0.001 & 0.000 & 0.059 \\
\hline SS accrual age 62 & 0.760 & 0.641 & 0.072 & -0.020 & 0.009 \\
\hline (\%) - subjective & 0.001 & 0.001 & 0.054 & 0.339 & 0.574 \\
\hline Current AIME & -0.013 & -0.011 & $-3.713 \mathrm{E}-04$ & $-2.895 \mathrm{E}-04$ & $-1.733 \mathrm{E}-04$ \\
\hline & 0.000 & 0.000 & 0.001 & 0.000 & 0.171 \\
\hline $\mathrm{t}=1998$ & 3.959 & 2.181 & 0.104 & -0.034 & 0.206 \\
\hline (ref: $\mathrm{t}=1996)$ & 0.099 & 0.133 & 0.172 & 0.516 & 0.066 \\
\hline $1-50 \%$ of $\mathrm{P}$ & -6.776 & 0.059 & -0.097 & -0.055 & -0.064 \\
\hline Control is no tax & -4.705 & -4.057 & -0.105 & -0.160 & -0.108 \\
\hline $51-99 \%$ of $\mathrm{P}$ & 0.187 & 0.098 & 0.518 & 0.054 & 0.559 \\
\hline & -14.991 & -12.723 & -0.286 & -0.262 & -0.486 \\
\hline $100 \%$ if $\mathrm{P}$ & 0.001 & 0.000 & 0.164 & 0.012 & 0.031 \\
\hline & -9.426 & -7.732 & -0.408 & -0.003 & 0.201 \\
\hline repeal $(\mathrm{REP}=1)$ & 0.079 & 0.045 & 0.111 & 0.982 & 0.431 \\
\hline Control is no tax & 1.963 & 1.253 & 0.114 & -0.161 & 0.383 \\
\hline $1-50 \%$ of P X REP & 0.640 & 0.632 & 0.437 & 0.098 & 0.049 \\
\hline & 9.927 & 5.944 & 0.448 & 0.047 & -0.090 \\
\hline $51-99 \%$ of P X REP & 0.053 & 0.058 & 0.010 & 0.688 & 0.698 \\
\hline & 10.388 & 7.505 & 0.229 & 0.113 & 0.217 \\
\hline $100 \%$ of P X REP & 0.040 & 0.015 & 0.169 & 0.329 & 0.342 \\
\hline & -4.431 & 3.033 & 0.018 & -0.059 & -0.375 \\
\hline constant & -24.851 & -2.351 & -0.880 & & -4.295 \\
\hline & 0.004 & 0.697 & 0.015 & & 0.000 \\
\hline age dummies & yes & yes & yes & yes & yes \\
\hline $\mathrm{N}$ & 4146 & 4146 & 4146 & 3791 & 3791 \\
\hline rho (share UH) & & 0.590 & 0.666 & & 0.462 \\
\hline
\end{tabular}




\begin{tabular}{|c|c|c|c|c|c|}
\hline covariate & tobit P65 & RE tobit P65 & $\begin{array}{c}\text { RE probit } \\
(\mathrm{P} 65>0)\end{array}$ & $\begin{array}{c}\text { Ordered Probit } \\
(\text { EC: < NRA, } \\
\text { NRA, >NRA)) }\end{array}$ & $\begin{array}{c}\text { RE probit } \\
(\mathrm{EC}>\mathrm{NRA})\end{array}$ \\
\hline widow & 13.594 & 11.553 & 0.342 & -0.058 & -0.357 \\
\hline (ref: married) & 0.000 & 0.000 & 0.006 & 0.442 & 0.072 \\
\hline \multirow[t]{2}{*}{ divorced } & 19.702 & 15.184 & 0.541 & 0.241 & 0.207 \\
\hline & 0.000 & 0.000 & 0.000 & 0.000 & 0.086 \\
\hline \multirow[t]{2}{*}{ never married } & 9.570 & 8.803 & 0.331 & 0.021 & -0.073 \\
\hline & 0.060 & 0.029 & 0.129 & 0.850 & 0.775 \\
\hline \multirow[t]{2}{*}{ black } & -12.847 & -10.125 & -0.333 & -0.251 & -0.387 \\
\hline & 0.000 & 0.000 & 0.003 & 0.000 & 0.014 \\
\hline \multirow[t]{2}{*}{ other race } & -3.127 & -2.927 & -0.001 & 0.239 & 0.114 \\
\hline & 0.548 & 0.480 & 0.997 & 0.030 & 0.664 \\
\hline \multirow[t]{2}{*}{ years schooling } & 3.211 & 2.556 & 0.112 & 0.054 & 0.111 \\
\hline & 0.000 & 0.000 & 0.000 & 0.000 & 0.000 \\
\hline \multirow[t]{2}{*}{ health good } & -4.291 & -2.303 & -0.107 & -0.039 & 0.009 \\
\hline & 0.029 & 0.107 & 0.106 & 0.372 & 0.920 \\
\hline \multirow[t]{2}{*}{ health fair/poor } & -7.728 & -4.824 & -0.281 & 0.117 & -0.128 \\
\hline & 0.017 & 0.047 & 0.014 & 0.122 & 0.456 \\
\hline \multirow[t]{2}{*}{ self-employed } & 24.386 & 17.424 & 0.632 & 0.175 & 0.281 \\
\hline & 0.000 & 0.000 & 0.000 & 0.006 & 0.036 \\
\hline \multirow[t]{2}{*}{ tenure current job } & -0.496 & -0.414 & -0.016 & -0.004 & -0.006 \\
\hline & 0.000 & 0.000 & 0.000 & 0.102 & 0.226 \\
\hline pressure to retire & -6.134 & -1.982 & -0.044 & -0.182 & -0.236 \\
\hline$<65$ from co-workers & 0.042 & 0.364 & 0.644 & 0.008 & 0.139 \\
\hline transition less & 5.961 & 3.515 & 0.095 & 0.184 & 0.337 \\
\hline demanding job poss. & 0.003 & 0.014 & 0.148 & 0.000 & 0.000 \\
\hline \multirow[t]{2}{*}{ 1st quntile wealth } & 12.048 & 8.666 & 0.241 & 0.186 & 0.192 \\
\hline & 0.000 & 0.000 & 0.030 & 0.007 & 0.187 \\
\hline 2nd quntile wealth & 7.182 & 3.564 & 0.119 & 0.071 & 0.012 \\
\hline (ref: 3rd quintile) & 0.006 & 0.059 & 0.172 & 0.229 & 0.922 \\
\hline \multirow{2}{*}{ 4th quntile wealth } & -9.005 & -6.605 & -0.241 & -0.060 & -0.145 \\
\hline & 0.001 & 0.000 & 0.005 & 0.307 & 0.229 \\
\hline \multirow[t]{2}{*}{5 th quntile wealth } & -16.844 & -11.380 & -0.334 & -0.130 & -0.186 \\
\hline & 0.000 & 0.000 & 0.001 & 0.042 & 0.160 \\
\hline has DB plan current & -11.278 & -6.832 & -0.207 & -0.173 & -0.336 \\
\hline job & 0.000 & 0.000 & 0.005 & 0.000 & 0.001 \\
\hline has DC plan current & 6.234 & 2.968 & 0.085 & 0.056 & -0.009 \\
\hline job & 0.002 & 0.037 & 0.202 & 0.208 & 0.920 \\
\hline \multirow[t]{2}{*}{ total $\mathrm{HH}$ income } & $1.29 \mathrm{E}-06$ & $-1.95 \mathrm{E}-06$ & 3.62E-09 & $3.18 \mathrm{E}-07$ & $2.34 \mathrm{E}-07$ \\
\hline & 0.837 & 0.657 & 0.987 & 0.009 & 0.162 \\
\hline Social Security wealth & $1.46 \mathrm{E}-04$ & $1.25 \mathrm{E}-04$ & $3.45 \mathrm{E}-06$ & 8.69E-06 & $7.35 \mathrm{E}-06$ \\
\hline age 62 - subjective & 0.014 & 0.008 & 0.154 & 0.000 & 0.018 \\
\hline SS accrual age 62 & 0.226 & 0.167 & 0.004 & 0.004 & 0.010 \\
\hline$(\%)$ - subjective & 0.089 & 0.112 & 0.485 & 0.210 & 0.148 \\
\hline Current AIME & -0.006 & -0.005 & $-1.54 \mathrm{E}-04$ & $-3.56 \mathrm{E}-04$ & $-2.56 \mathrm{E}-04$ \\
\hline & 0.023 & 0.009 & 0.141 & 0.000 & 0.041 \\
\hline $\mathrm{t}=1998$ & -0.379 & -0.810 & 0.118 & -0.153 & 0.017 \\
\hline (ref: $\mathrm{t}=1996)$ & 0.868 & 0.586 & 0.059 & 0.002 & 0.865 \\
\hline $1-50 \%$ of $\mathrm{P}$ & 1.154 & 0.478 & 0.114 & -0.181 & -0.168 \\
\hline Control is no tax & 0.706 & 0.836 & 0.338 & 0.008 & 0.289 \\
\hline $51-99 \%$ of $\mathrm{P}$ & 4.066 & 2.989 & 0.296 & -0.077 & 0.154 \\
\hline & 0.352 & 0.368 & 0.091 & 0.421 & 0.472 \\
\hline $100 \%$ if $\mathrm{P}$ & 6.894 & 6.197 & 0.579 & -0.121 & 0.034 \\
\hline & 0.380 & 0.280 & 0.071 & 0.468 & 0.920 \\
\hline repeal $(\mathrm{REP}=1)$ & 8.225 & 4.630 & 0.326 & -0.291 & 0.195 \\
\hline Control is no tax & 0.007 & 0.026 & 0.000 & 0.000 & 0.171 \\
\hline $1-50 \%$ of P X REP & 1.810 & 2.394 & 0.127 & 0.126 & 0.101 \\
\hline & 0.644 & 0.360 & 0.264 & 0.167 & 0.571 \\
\hline $51-99 \%$ of P X REP & 0.458 & 1.956 & 0.066 & 0.074 & -0.171 \\
\hline & 0.925 & 0.550 & 0.647 & 0.496 & 0.388 \\
\hline $100 \%$ of P X REP & -6.206 & -2.709 & -0.365 & -0.225 & -0.164 \\
\hline & 0.617 & 0.736 & 0.339 & 0.396 & 0.702 \\
\hline constant & -47.681 & -26.799 & -1.633 & & -4.022 \\
\hline & 0.000 & 0.000 & 0.000 & & 0.000 \\
\hline age dummies & yes & yes & yes & yes & yes \\
\hline $\mathrm{N}$ & 5306 & 5306 & 5306 & 4363 & 4363 \\
\hline rho (share UH) & & 0.447 & 0.632 & & 0.439 \\
\hline
\end{tabular}




\section{Appendix: P(62) Results}

\begin{tabular}{|c|c|c|c|}
\hline Males & tobit $\mathrm{P} 62$ & RE tobit $\mathrm{P} 62$ & $\begin{array}{c}\text { RE probit } \\
(\mathrm{P} 62>0)\end{array}$ \\
\hline repeal $(\mathrm{REP}=1)$ & 4.596 & 2.756 & 0.273 \\
\hline Control is no tax & $(0.332)$ & $(0.364)$ & $(0.065)$ \\
\hline \multicolumn{4}{|l|}{ Groups X REP } \\
\hline $1-50 \%$ of $\mathrm{P}$ & $\begin{array}{c}1.193 \\
(0.837)\end{array}$ & $\begin{array}{c}0.453 \\
(0.901)\end{array}$ & $\begin{array}{c}0.031 \\
(0.863)\end{array}$ \\
\hline $51-99 \%$ of $\mathrm{P}$ & $\begin{array}{c}2.798 \\
(0.622)\end{array}$ & $\begin{array}{c}1.536 \\
(0.665)\end{array}$ & $\begin{array}{c}0.007 \\
(0.968)\end{array}$ \\
\hline $100 \%$ if $\mathrm{P}$ & $\begin{array}{l}-6.703 \\
(0.536)\end{array}$ & $\begin{array}{c}5.022 \\
(0.458)\end{array}$ & $\begin{array}{l}-0.392 \\
(0.237)\end{array}$ \\
\hline $\mathrm{N}$ & 4146 & 4146 & 4146 \\
\hline
\end{tabular}

Notes: Sample of workers aged 51-61 from 1996 to 2002. Pvalue under parameter estimates. P62 is the subjective probability to work full-time past 62 .

\begin{tabular}{|c|c|c|c|}
\hline Females & tobit $\mathrm{P} 62$ & RE tobit $\mathrm{P} 62$ & $\begin{array}{c}\text { RE probit } \\
(\mathrm{P} 62>0)\end{array}$ \\
\hline repeal $(\mathrm{REP}=1)$ & 5.773 & 2.757 & 0.316 \\
\hline Control is no tax & $(0.083)$ & $(0.213)$ & $(0.001)$ \\
\hline \multicolumn{4}{|l|}{ Groups X REP } \\
\hline $1-50 \%$ of $\mathrm{P}$ & $\begin{array}{c}0.407 \\
(0.924)\end{array}$ & $\begin{array}{c}1.022 \\
(0.713)\end{array}$ & $\begin{array}{c}0.069 \\
(0.563)\end{array}$ \\
\hline $51-99 \%$ of $\mathrm{P}$ & $\begin{array}{l}-1.198 \\
(0.824)\end{array}$ & $\begin{array}{l}1.328 \\
(0.706)\end{array}$ & $\begin{array}{c}-0.143 \\
(0.350)\end{array}$ \\
\hline $100 \%$ if $\mathrm{P}$ & $\begin{array}{c}-10.449 \\
(0.448)\end{array}$ & $\begin{array}{l}-3.615 \\
(0.684)\end{array}$ & $\begin{array}{l}-0.069 \\
(0.867)\end{array}$ \\
\hline $\mathrm{N}$ & 5306 & 5306 & 5306 \\
\hline
\end{tabular}

Notes: Sample of workers aged 51-61 from 1996 to 2002. Pvalue under parameter estimates. P62 is the subjective probability to work full-time past 62 . 